\title{
Oligomer formation in the troposphere: from experimental knowledge to 3-D modeling
}

\author{
Vincent Lemaire $^{1}$, Isabelle Coll ${ }^{1}$, Florian Couvidat ${ }^{2}$, Camille Mouchel-Vallon $^{1, a}$, Christian Seigneur ${ }^{3}$, and \\ Guillaume Siour ${ }^{1}$ \\ ${ }^{1}$ LISA/IPSL, Laboratoire Interuniversitaire des Systèmes Atmosphériques, UMR CNRS 7583, \\ Université Paris Est Créteil (UPEC) et Université Paris Diderot (UPD), 94010 Créteil, France \\ ${ }^{2}$ INERIS, Institut National de l'Environnement Industriel et des Risques, Parc technologique ALATA, \\ 60550 Verneuil en Halatte, France \\ ${ }^{3}$ CEREA, Joint Laboratory Ecole des Ponts ParisTech/EDF R\&D, Université Paris-Est (UPE), \\ 77455 Marne la Vallée, France \\ ${ }^{a}$ now at: Wolfson Atmospheric Chemistry Laboratories, Department of Chemistry, University of York, York, UK \\ Correspondence to: Isabelle Coll (isabelle.coll@lisa.u-pec.fr)
}

Received: 26 August 2015 - Published in Geosci. Model Dev. Discuss.: 28 October 2015

Revised: 1 March 2016 - Accepted: 16 March 2016 - Published: 11 April 2016

\begin{abstract}
The organic fraction of atmospheric aerosols has proven to be a critical element of air quality and climate issues. However, its composition and the aging processes it undergoes remain insufficiently understood. This work builds on laboratory knowledge to simulate the formation of oligomers from biogenic secondary organic aerosol (BSOA) in the troposphere at the continental scale. We compare the results of two different modeling approaches, a first-order kinetic process and a $\mathrm{pH}$-dependent parameterization, both implemented in the CHIMERE air quality model (AQM) (www.lmd.polytechnique.fr/chimere), to simulate the spatial and temporal distribution of oligomerized secondary organic aerosol (SOA) over western Europe. We also included a comparison of organic carbon (OC) concentrations at two EMEP (European Monitoring and Evaluation Programme) stations. Our results show that there is a strong dependence of the results on the selected modeling approach: while the irreversible kinetic process leads to the oligomerization of about $50 \%$ of the total BSOA mass, the $\mathrm{pH}$-dependent approach shows a broader range of impacts, with a strong dependency on environmental parameters ( $\mathrm{pH}$ and nature of aerosol) and the possibility for the process to be reversible. In parallel, we investigated the sensitivity of each modeling approach to the representation of SOA precursor solubility (Henry's law constant values). Finally, the pros and cons of each approach for the representation of SOA aging are discussed and recom-
\end{abstract}

mendations are provided to improve current representations of oligomer formation in AQMs.

\section{Introduction}

Due to their fast evolution in the troposphere and their continuous interaction with the ambient gas phase, atmospheric aerosols present a highly variable chemical composition in space and time (Q. Zhang et al., 2007). They not only comprise large quantities of inorganic species such as nitrates and sulfates, but also contain an organic fraction (organic aerosol, OA), made of condensed semi-volatile and low volatility organic species presenting a wide range of oxidation degrees (Jimenez et al., 2009). Part of this OA comes from the emission of particulate organic compounds into the atmosphere during combustion processes: it is called primary organic aerosol (POA). However, away from combustion emission sources, most of the OA arises from the oxidation of gas-phase organic species, making up the secondary organic aerosol (SOA), which may represent up to $70 \%$ of OA on a mass basis (Kanakidou et al., 2005). The diversity in size and composition of atmospheric aerosols induces major differences in their physicochemical properties (Molnar and Meszaros, 2001; Kanakidou et al., 2005). These properties affect their impact on the radiative balance of the atmosphere 
(Stier et al., 2007; Paredes-Miranda et al., 2009) and their adverse health effects (Fuzzi et al., 2006). Thus, not only the total aerosol mass, but also their size distribution and their chemical content are of crucial importance for atmospheric issues. Although major scientific advances have been made during the last decade, the composition and the aging processes of the organic aerosol fraction remain insufficiently understood (e.g., Volkamer et al., 2006).

As a consequence, air quality models (AQMs), despite significant progress, still have difficulties to quantitatively reproduce the observed particulate matter (PM) levels and gradients, and continue to underestimate the formation of SOA in the troposphere, from cities to remote areas (Shrivastava et al., 2011; Ervens et al., 2011; Petetin et al., 2014). In this regard, the chemistry of organics in the aqueous condensed phase remains poorly characterized. Thanks notably to atmospheric simulation chamber data, new processes have been integrated into AQMs so as to fill the gap between models and observations. These processes include, for example, the addition of new precursors (e.g., Y. Zhang et al., 2007), the treatment of SOA hygroscopicity (e.g., Pun, 2008) and aqueous chemistry SOA formation pathways (e.g., Carlton et al., 2008). In doing so, oligomerization was highlighted as one of the most important identified processes of SOA evolution. Laboratory studies indeed showed that oligomerization could be a quantitatively important evolution pathway for aqueous condensed species, and may greatly contribute to a better understanding of SOA aging (e.g., Kalberer et al., 2004; Jang et al., 2005; Trump and Donahue, 2014 and references therein). In particular, modeling studies have shown that the oligomerization of biogenic oxidized compounds happens to be a significant source of secondary organic aerosols (Aksoyoglu et al., 2011).

Based on these experimental results, two distinct approaches aiming at representing oligomerization into AQMs have initially been developed. One approach, described by Carlton et al. (2010), proposes to represent the formation of oligomers observed in simulation chambers by using a first-order rate constant for all organic compounds in the organic and aqueous aerosol phases. In parallel, Pun and Seigneur (2007) developed a pH-dependent oligomer formation, based on the experimental data of Jang et al. (2005), which applies only to the aldehyde species dissolved in the aerosol aqueous phase. Note that chemistry in cloud droplets is not considered in our study. More recently, Trump and Donahue (2014) also used an equilibrium approach to model oligomer formation within the volatility basis set (VBS) formulation. Although these approaches rely on two very different concepts, they both aim to produce oligomers in the aerosol phase from the particle-phase reactions of condensed semi-volatile organic species, using empirical relationships. These parameterizations have been implemented in several AQMs such as CAMx (www.camx.com), CMAQ (http://www.cmaq-model.org) and Polyphemus (http://cerea. enpc.fr/polyphemus/index.html) in order to improve the sim- ulated SOA concentration fields. Several modeling studies including these new parameterizations were conducted (Pun and Seigneur, 2007; Carlton et al., 2010; Aksoyoglu et al., 2011; Couvidat et al., 2012); it came out that oligomerization of biogenic oxidation products is mostly responsible for SOA formation and that the implementation of this process in AQMs reduces the discrepancy between the PM simulated mass and measurements in Europe and North America. However, although enhanced operational SOA modeling is needed, there still are no in situ measurements of oligomers that would increase our understanding of their formation and either allow the validation of these approaches or enable further refinement of the models. As an example, Pun and Seigneur (2007) indicated that their approach may overestimate the role of water in this process, as it is not currently known whether all liquid water present in aerosols is available to interact with organic compounds. Furthermore, as the two methods diverge both on the set of species submitted to oligomerization and on the nature of the driving parameters (kinetic constant versus equilibrium relationship), we also can expect the modeled distribution of simulated oligomers to differ between the two approaches.

To our knowledge, these approaches have not yet been compared in a same model. Such an initiative seems warranted, first not only to identify the range of uncertainties that these two parameterizations induce in the model outputs, but also to define how these parameterizations influence our understanding of SOA production in time and space. Thus, this work aims at investigating the representation of oligomerization that is provided by operational models. It consists in a model sensitivity study using, in turn, each oligomerization approach presented above to quantify the production of organic PM over Europe in the lower troposphere through continuous simulation. Moreover, it includes a study of the impact of the Henry's law constant computation for complex organic species, which is considered as a key parameter in representing the multiphase behavior of organic compounds in the atmosphere (Raventos-Duran et al., 2010). This study was conducted with the CHIMERE AQM (www.lmd.polytechnique.fr/chimere) at the continental scale over Europe during a summer period covering July and August 2006. The simulated SOA yields, as well as the oligomer spatial and temporal distribution, obtained in each model configuration are compared so as to learn about the corresponding approaches.

This work is divided into three parts. First, the methodology and the model configurations are presented. Next the influence of the Henry' law constant on gas-particle partitioning, as well as the impact of each parameterization on the SOA budget are discussed and are compared against field measurements. Finally, we discuss the assets and limitations of both oligomer modeling approaches and provide recommendations for future work. 


\section{Methodology and model setup}

\subsection{Model setup}

This study uses the CHIMERE AQM, which is designed to produce daily forecasts of ozone, PM and other pollutants and to conduct pollution event analyses and research studies in atmospheric chemistry (Menut et al., 2013). The model may be run from the regional to the continental scale, with horizontal resolutions ranging from 1 to $100 \mathrm{~km}$. CHIMERE is used daily for operational air quality forecasts in nine different regions of France and Europe. In this context, model performance is assessed every day via the comparison of the model output with atmospheric measurements, which also provides the basis for the ongoing improvement of CHIMERE. CHIMERE uses the MELCHIOR2 gas-phase chemical scheme (120 reactions among 44 gaseous species), which is adapted from the original EMEP (European Monitoring and Evaluation Programme) mechanism and is a reduced version of the MELCHIOR1 mechanism, obtained by Carter's surrogate molecule method (Carter, 1990). The gasphase chemical mechanism for SOA production has been described in detail by Pun et al. (2006) and Bessagnet et al. (2008).

In CHIMERE, a sectional aerosol module provides the evolution of the concentrations of seven particulate groups of species: primary PM, nitrate, sulfate, ammonium, biogenic SOA, anthropogenic SOA and water (Schmidt et al., 2001; Bessagnet et al., 2004, 2009). The size distribution of aerosol particles is represented using eight size sections ranging from $10 \mathrm{~nm}$ to $40 \mu \mathrm{m}$. Physical processes taken into account are coagulation (Gelbard and Seinfeld, 1980), condensation via absorption (Nenes et al., 1998; Pun et al., 2006) and nucleation for sulfuric acid (Kulmala et al., 1998). The equilibrium concentrations of inorganic species are computed by the thermodynamic module ISORROPIA (http: //nenes.eas.gatech.edu/ISORROPIA) (version 1.7) presented in Nenes et al. (1998). The distribution of secondary organic species between the gas and particulate phases is calculated using Raoult's law with a temperature-dependent partitioning coefficient as described by Pankow (1994) for hydrophobic species and using Henry's law for hydrophilic species (Pun et al., 2006). In this version of the CHIMERE model, SOA formation is processed through the oxidation of five biogenic gaseous precursor species (isoprene, $\alpha$-pinene, $\beta$ pinene, limonene and ocimene) and four anthropogenic precursor species (benzene, toluene, trimethylbenzene and a species accounting for C4-C10 alkanes). As for condensable species, both hydrophilic (condensation following Henry's law) and hydrophobic (condensation following Raoult's law) behaviors are considered, they are represented by

- six hydrophilic surrogate species including an anthropogenic non-dissociative species (AnA0D), an anthropogenic once-dissociative species (AnA1D), an anthropogenic twice-dissociative species (AnA2D), a bio- genic non-dissociative species (BiA0D), a biogenic once-dissociative species (BiA1D) and a biogenic twice-dissociative species (BiA2D). The pAnA* ${ }^{*}$ and $\mathrm{pBiA}^{*} \mathrm{D}$ species stand for the part of the surrogate species that is present in the particulate phase;

- three hydrophobic species comprising two anthropogenic species with low and moderate saturation vapor pressures (AnBlP and $\mathrm{AnBmP}$ ) and a biogenic species with a moderate saturation vapor pressure $(\mathrm{BiBmP})$;

- two water-soluble surrogate species that account for the isoprene oxidation products (ISOPA1, ISOPA2). The oxidation of isoprene is adapted from the formulation prescribed by Kroll et al. (2006) and Y. Zhang et al. (2007).

Note that if - for any time step and grid cell - the modeled aerosol is not deliquescent, the gas-aerosol partition of the hydrophilic species will then be driven by their saturation vapor pressure. That is, their condensation will follow Raoult's law.

In the model, horizontal advection is calculated using the Van Leer second-order scheme and boundary layer turbulence is represented as a diffusion phenomenon, following Troen and Mahrt (1986). Vertical winds are diagnosed through a bottom-up mass balance scheme. Dry deposition is coded as in Wesely (1989) and photolytic rates are attenuated using liquid water or relative humidity. Finally, the numerical time solver uses the TWOSTEP method (Verwer, 1994).

The 2006 annual anthropogenic emissions from the EMEP database (Vestreng et al., 2005) at a resolution of $0.5^{\circ} \times 0.5^{\circ}$ have been used (http://www.emep.int). They include $\mathrm{CO}$, $\mathrm{NH}_{3}, \mathrm{NMVOC}, \mathrm{NO}_{x}, \mathrm{SO}_{x}$ and $\mathrm{PM}$ emissions for the 10 anthropogenic activity sectors of the Selected Nomenclature for Air Pollution (SNAP). The emission values are disaggregated into individual chemical species and at an hourly time step according to IER recommendations, and are spatially distributed over our simulation domain using a kilometric land use database (http://www.glcf.umiacs.umd.edu). Biogenic emissions have been computed with the MEGAN model (Guenther et al., 2006) using a land use database of $1 \mathrm{~km}$ resolution and hourly meteorological parameters from the MM5 model (see below) for the calculation of the various biogenic volatile organic compounds (VOC) emission flux intensity and temporal evolution (http://lar.wsu.edu/megan/). Climatologic LMDZ (Hauglustaine et al., 2004) model output data were used for boundary conditions. Finally, the mesoscale model MM5 (Dudhia, 1993) was used to generate hourly meteorological fields for CHIMERE over a European domain covering our simulation domain, with a horizontal resolution of $54 \mathrm{~km}$ and using 32 levels in the vertical direction from the surface to $10 \mathrm{hPa}$.

A European domain extending from $6^{\circ} \mathrm{W}$ to $20^{\circ} \mathrm{E}$ in longitude and from $38^{\circ}$ to $54^{\circ} \mathrm{N}$ in latitude (see Fig. 1) was defined for this study: its size allows for tracking and study- 


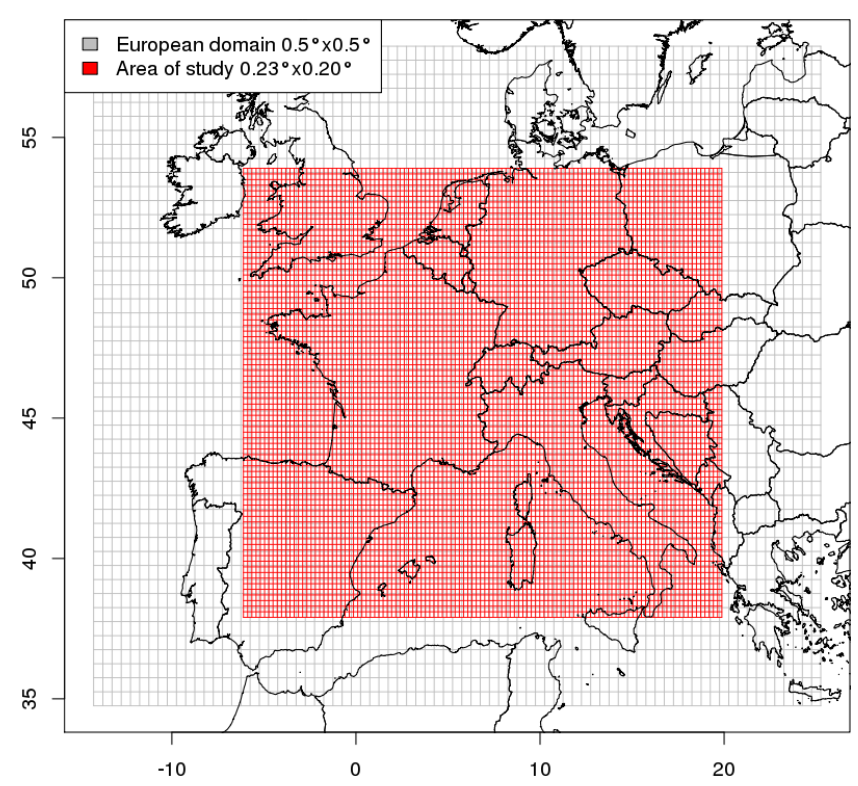

Figure 1. In red, gridded domain used for the air quality simulations, having a horizontal resolution of $0.23^{\circ} \times 0.20^{\circ}$. In black, large-scale domain used to provide boundary conditions (horizontal resolution of $0.5^{\circ} \times 0.5^{\circ}$ ).

ing large European city plumes and the domain includes our study area, which is western Europe. The horizontal resolution is $0.23^{\circ} \times 0.20^{\circ}$. For the vertical resolution, we used eight levels of decreasing resolution from the ground level up to $500 \mathrm{hPa}$, the first model layer being $50 \mathrm{~m}$ thick. The simulation domain and its grid are illustrated in Fig. 1. The simulation period covers 2 months (July and August) in the summer of 2006. The simulation was run with a spin-up period (15 days) prior to the periods of interest in order to ensure that emissions and secondary pollutants are realistically distributed over the domain at the beginning of the evaluation period.

\subsection{Oligomer parameterizations}

This section describes the implementation of oligomer production in CHIMERE using the two existing parameterizations and their associated hypotheses.

\subsubsection{Kinetic approach}

The first approach (called hereafter KIN) is based on the hypothesis that oligomer formation may be represented through a kinetic process (Morris et al., 2006; Carlton et al., 2010). This hypothesis is supported by a series of smog chamber experiments conducted by Kalberer et al. (2004), where an important fraction of organic aerosol mass was shown to be composed of oligomers. The authors reported that, after $20 \mathrm{~h}$ of processing, $50 \%$ of the total organic aerosol mass was transformed into oligomers. From this result, Morris et al. (2006) proposed the use of a first-order rate constant $k_{1}=9.6 \times 10^{-6} \mathrm{~s}^{-1}$ to account for the oligomerization formation process, corresponding to a half-life of $20 \mathrm{~h}$ for organic species in the particulate phase. In this approach, biogenic and anthropogenic species are all potential oligomer precursors. However, due to low amounts of anthropogenic semivolatile organic compounds (SVOC) from the oxidation of classic precursors (Toluene, Xylene, Trimethylbenzene, etc.) over Europe, the production of anthropogenic oligomer could be negligible (Aksoyoglu et al., 2011).

To transcribe this approach in the model, we have allocated a first-order oligomer production kinetics to all the hydrophobic and hydrophilic surrogate species (AnA0-12D and BiA0-1-2D, AnB1P, AnBmP, BiBmP, ISOPA1 and ISOPA2) of the CHIMERE aerosol module. Preliminary simulations with CHIMERE confirmed the precedent findings, i.e., a very low budget of oligomers of anthropogenic origin (concentrations reach $10^{-3} \mathrm{ng} \mathrm{m}^{-3}$ at the maximum over the domain) compared with biogenic oligomers (which concentrations reach a few $\mu \mathrm{g} \mathrm{m}^{-3}$ for oligomers over many continental areas).

Thus, for simplification, only the six biogenic surrogate species (BiA0D, BiA1D, BiA2D, BiBmP, ISOPA1 and ISOPA2) were considered here (Gas-phase chemical scheme for SOA formation is available in Table 6 of Menut et al., 2013). Furthermore, as will be discussed below, our study will focus on monoterpenes, a common species of both modeling approaches. To that end, a new species family called BiOLG, representing the total sum of oligomerized $\mathrm{pBiA}^{*} \mathrm{D}$ compounds, was introduced in CHIMERE. It accounts for oligomer formation from the oxidation of monoterpenes only and will be the basis for the intercomparison of the two approaches.

In this empirical parameterization, oligomerization is considered as an irreversible process. This approach has the advantage of simplicity, as it proposes a similar chemical reactivity for all organic oligomer precursors in the particulate phase (hydrophilic and hydrophobic species), one single chemical pathway for oligomer formation, and only one type of oligomer product. However, the drawback of this method is that it does not account for the details of the gas-phase SVOC speciation, for the variability of the aerosol nature (deliquescent aerosol or not), nor for ambient parameters such as $\mathrm{pH}$. Thus, it may lead to biases in the quantitative estimation of oligomer and OA production. Moreover, owing to the choice of a kinetic approach with a half life of $20 \mathrm{~h}$, oligomer production is expected to be dominant away from source areas (except in the presence of severe anticyclonic conditions), enhancing the role of pollutant transport.

\subsection{2 pH-dependant approach}

The second approach (called here KPH) combines the laboratory works of Jang et al. (2005) - who showed that the polymerization of aldehydes may happen through a variety 
of acid-catalyzed reactions - and the observations of Gao et al. (2004) - who indicated that at least $10 \%$ of the total organic aerosol mass is converted into oligomers due to the formation of organic acids in the aerosol. From these results, Pun and Seigneur (2007) developed an equation for the calculation of the gas-to-particle partitioning constant of semivolatile aldehydes. It represents their increased partitioning toward the aqueous phase due to acidity:

$K_{\mathrm{p}, \mathrm{eff}, i}=K_{\mathrm{p}, i}\left[1+K_{0, \mathrm{eff}, i, \text { ref }} \times\left(\frac{C_{\mathrm{H}^{+}}}{C_{\mathrm{H}^{+}, \text {ref }}}\right)^{1.91}\right]$,

where $K_{\mathrm{p}, \text { eff, } i}$ is the effective partitioning coefficient of the $i$ th compound between the gas phase and the aerosol aqueous phase; $K_{\mathrm{p}, i}$ is its standard partitioning coefficient - calculated for non-acidic conditions - and $C_{\mathrm{H}^{+}}$represent the aqueous concentration of hydronium ions. In this approach, $C_{\mathrm{H}^{+}}$,ref is set to $10^{-6} \mathrm{~mol} \mathrm{~L}^{-1}$ and $K_{0, \text { eff, } i \text {,ref stands for the }}$ value of 0.1 found by Gao et al. (2004) under the $C_{\mathrm{H}^{+}, \text {ref }}$ conditions. According to the results of Jang et al. (2005), aldehydes appear to be more reactive than ketones by 2 orders of magnitude. To simplify the parameterization, Pun and Seigneur (2007) considered as a first approximation that only aqueous aldehydes undergo oligomerization. In our model, it is equivalent to assuming that only BiA0D surrogates can lead to oligomer formation. Such a consideration derives from the fact that isoprene oxidation products in CHIMERE are not associated with a given molecular structure. Thus, oligomerization processes could not be attributed to isoprene surrogates without more chemical details here, using the KPH approach. Our study then focuses on what can be learned from oligomerization modeling approaches on the basis of monoterpene surrogate reactivity.

The KPH approach only artificially reproduces oligomer production. Indeed, the reactivity in the particulate phase that leads to the consumption of dissolved organic species it restituted by an increase in the value of their effective partitioning coefficient, according to Eq. (1). As a consequence, oligomerization is treated here as a fully reversible process. Furthermore, this approach does not require any new model species to represent the aqueous oligomers. This is why it is necessary to perform two types of simulations to estimate the effect of the oligomerization process: a reference case called hereafter REF - and a scenario case (KPH). The differences in the pBiA0D concentration fields between the two simulations represent aqueous oligomerization in the KPH approach:

$[$ Oligomers $]=[\mathrm{pBiA0D}]_{\mathrm{KPH}}-[\mathrm{pBiA} 0 \mathrm{D}]_{\mathrm{REF}}$.

To implement this approach in the model and ensure the robustness of the modified partitioning constant value, it was necessary to adequately account for the acidity of the deliquescent particles. The particle $\mathrm{pH}$ is calculated in CHIMERE by an online coupling with the ISORROPIA model that solves the transition between solid and aqueous phases through the estimation of the deliquescent relative humidity. However, it is also possible to run ISORROPIA in a metastable configuration, which considers that aerosols remain in a liquid state under conditions of low relative humidity, thus avoiding the transfer of dissolved BiA0D back to the gas phase and favoring oligomer persistence as well as its atmospheric transport. This alternative is taken into account for the evaluation of the KPH approach.

ISORROPIA model also provides - for each cell and at every time step of the model calculation - particle water content and ion species equilibrium concentrations. At the end of the ISORROPIA computation, we constrained the particle $\mathrm{pH}$ to a range of values between 2 and 6 . The upper value limit of 6 allows us to be consistent with the parameterization and to avoid partitioning constant values lower than that of the reference (see Eq. 1). The lower limit was set for numerical reasons, as the transfer of the concerned organic species to the aqueous phase becomes total under a $\mathrm{pH}$ of 2 .

\subsection{Module implementation}

As mentioned in the previous section, isoprene oxidation products could not be considered as oligomer precursors in the $\mathrm{pH}$-dependent approach, due to the absence of structural information on these species in the gaseous chemical scheme. A refined chemical scheme for isoprene oxidation in CHIMERE is under development (Couvidat and Seigneur, 2011) and will be included later in the model. Pending this future model development, we focus here on a comparative evaluation of oligomerization of monoterpene oxidation products using the two parameterizations described above. Nevertheless, the absence of molecular structure allocation for ISOPA1 and ISOPA2 (model oxidation products of isoprene) is not a limiting factor for the kinetic approach. Thus, considerations for the relative importance of kinetic oligomer production from monoterpenes and isoprene will be presented in Sect. 3.

One important issue in SOA production is the influence of the gas-particle partition of semi-volatile species on the final model results, whether under dry or wet conditions. However, since this work focuses on the reactivity of hydrophilic compounds, we specifically addressed the issue of Henry's constant values, $K_{\mathrm{H}}$. By affecting the fraction of the semi-volatile species that partition into the aqueous phase, this constant directly impacts the quantitative production of the organic aerosol fraction. Furthermore, the reliability of $K_{\mathrm{H}}$ values is known to be low for complex compounds of atmospheric interest, especially for highly soluble species (Raventos-Duran et al., 2010). In order to observe the effect of refining these values in the different approaches, we ran the model with different sets of $K_{\mathrm{H}}$ values. To that end, the group contribution method of Suzuki et al. (1992) that is used by default in CHIMERE to produce $K_{\mathrm{H}}$ values at $298 \mathrm{~K}$ was replaced by the GROMHE group contribution approach. This 
Table 1. Properties of the biogenic hydrophilic and hydrophobic surrogate SOA species used in the simulations conducted with the CHIMERE model.

\begin{tabular}{llrrrrr}
\hline $\begin{array}{l}\text { Surrogate } \\
\text { species }\end{array}$ & $\begin{array}{l}\text { Molecular } \\
\text { structure }\end{array}$ & $\begin{array}{r}\text { Molar mass } \\
\left(\mathrm{g} \mathrm{mol}^{-1}\right)\end{array}$ & $\begin{array}{r}\text { Henry's law constant } \\
\left(\mathrm{Matm}^{-1} \text { at } 298 \mathrm{~K}\right)\end{array}$ & $\begin{array}{r}\text { Saturation vapor } \\
\text { pressure }^{\mathrm{b}}(\mathrm{atm})\end{array}$ & $\begin{array}{l}\text { Considered } \\
\text { in KIN }^{\mathrm{c}}\end{array}$ & $\begin{array}{l}\text { Considered } \\
\text { in KPH }^{\mathrm{c}}\end{array}$ \\
\hline BiA0D & Pinonaldehyde & 168 & $4.97 \times 10^{4}$ & $3.55 \times 10^{-7}$ & Yes & Yes \\
BiA1D & Norpinic acid & 170 & $6.85 \times 10^{8}$ & $2.86 \times 10^{-10}$ & Yes & No \\
BiA2D & Pinic acid & 186 & $6.03 \times 10^{8}$ & $1.88 \times 10^{-10}$ & Yes & No \\
BiBmP & C15 oxo aldehyde & 236 & $10^{-2}$ & $3.97 \times 10^{-9}$ & Yes & No \\
\hline
\end{tabular}

${ }^{a}$ The Henry's law constants are calculated with the group contribution approach, GROMHE. ${ }^{b}$ Pun et al. (2006). ${ }^{c}$ Surrogate undergoing oligomerization.

method was developed by Raventos-Duran et al. (2010). It is based on the molecular structure and was shown to be more reliable than the standard methods for the complex organic compounds of atmospheric interest. In this context, an issue that must be addressed is that of the ideality of aqueous solutions. Indeed, due to the presence of inorganic salts at high concentrations, it is highly probable that the aqueous aerosol phase is non-ideal, which may affect Henry's law constants by 1 to 2 orders of magnitude. This phenomenon can be taken into account using Setschenow coefficients (Wang et al., 2015). However, figuring out the existing uncertainty on the aerosol aqueous-phase composition, and the fact that the uncertainty in the estimation of Henry's law constants using the group contribution approach may be about at least 1 order of magnitude (Raventos-Duran et al., 2010), we have considered that the correction brought by Setschenow coefficients would have a second-order effect, most probably poorly controlled due to the lack of accuracy on the aqueous-phase description and the margin of uncertainty on the coefficients themselves. This is why we did not include a non-ideality correction in the $K_{\mathrm{H}}$ evaluation process. In any case, the sensitivity tests that we conducted during these works will allow us to assess the necessary degree of sophistication on Henry's law constant values, and to identify areas for improvement.

By default, the molecular structure selected for BiA0D in CHIMERE is that of pinonaldehyde, a 10-carbon-atom molecule with an oxo group and an aldehyde group, while BiA1D and BiA2D are respectively based on norpinic acid (9-carbon-atom molecule with a carboxy group and an oxo group) and on pinic acid (9-carbon-atom molecule with two carboxy groups). Table 1 summarizes the default structure properties and molar masses, as well as the partitioning and saturation pressure characteristics used in CHIMERE for the three hydrophilic surrogates that lead to oligomer production from monoterpenes.

In order to evaluate the importance of considering a given molecular structure for each of these surrogate species, we computed different $K_{\mathrm{H}}$ values for them, corresponding to the different molecular structures they implicitly account for. The importance of investigating $K_{\mathrm{H}}$ values for our study is demonstrated in Sect. 3.1.1. Then, following the discussion of the results of the standard oligomerization approaches, we will discuss the results of additional oligomerization simulations conducted using a range of possible $K_{\mathrm{H}}$ values. These sensitivity tests are presented in detail in Sect. 3.2.

\section{Results}

\subsection{Model approaches for oligomer formation}

\subsubsection{Precursor partitioning in the reference case}

In order to examine the gas-particle partition of the model surrogates, we report in Fig. 2 the average concentration fields of the hydrophilic and hydrophobic surrogates simulated by CHIMERE in the reference case for the period 20 July-3 August 2006. This figure indicates that BiA1D is the highest hydrophilic contributor to the organic aerosol mass concentration, while BiA0D remains quasi-exclusively in the gas phase. However, among the monoterpene surrogates, the hydrophobic species $\mathrm{BiBmP}$ is the largest contributor to the organic aerosol mass concentration. On average, hydrophilic and hydrophobic species account for 25 and $75 \%$ of this organic aerosol mass concentration, respectively.

As the impact of the $K_{\mathrm{H}}$ partitioning constant value is likely to be important for the formation of oligomers, we focused on gaseous hydrophilic species and on the processes governing their transfer toward the particulate phase. To that end, we analyzed two different situations. In the first one, the aerosol is treated as a deliquescent aerosol where the distribution of the hydrophilic species between the gas and the condensed phases is driven by Henry's law. In the second one, we consider a dry aerosol where the partition of hydrophilic species is driven by Raoult's law.

For the deliquescent aerosol situation, we calculated the partitioning coefficient as described by Mouchel-Vallon et al. (2013), where the fraction of the surrogate species in the aqueous phase is obtained as follows:

$$
\xi^{i}=\frac{C_{a}^{i}}{C_{a}^{i}+C_{\mathrm{g}}^{i}}=\left(1+\frac{1}{H_{i} R T L}\right)^{-1} .
$$




\section{Gaseous Phase $\left(\mu \mathrm{g} \mathrm{m}^{-3}\right)$}

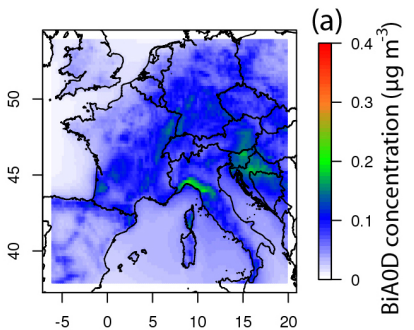

Aerosol Phase $\left(\mu \mathrm{g} \mathrm{m}^{-3}\right)$
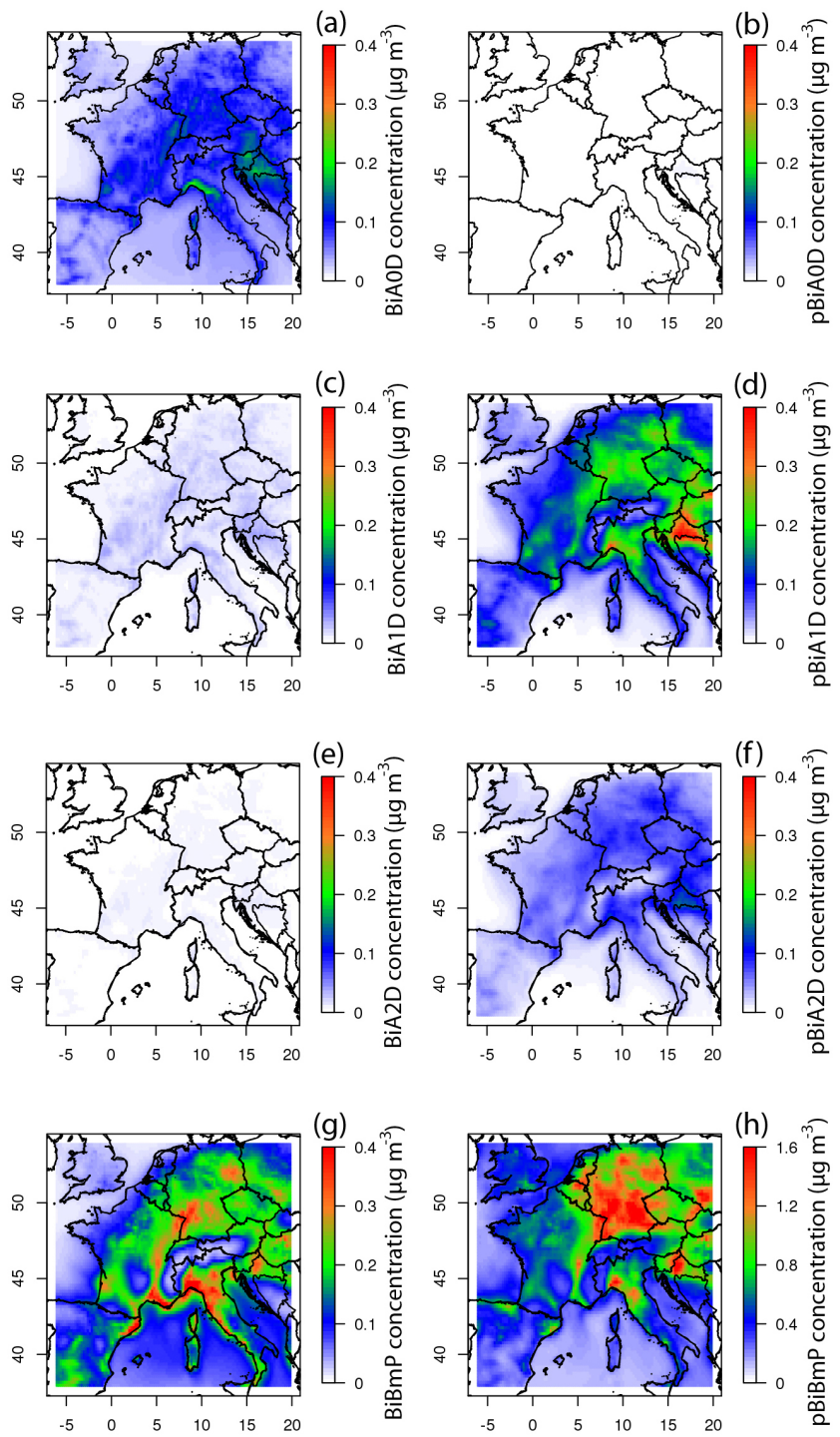

Figure 2. Mass concentration fields of BiA0D (a, b), BiA1D (c, d), $\operatorname{BiA} 2 \mathrm{D}(\mathbf{e}, \mathbf{f})$ and $\operatorname{BiBmP}(\mathbf{g}, \mathbf{h})$ in the gas (left) and particulate (right) phases, modeled by CHIMERE and averaged over 20 July3 August 2006.

In this equation, $C_{a}^{i}$ and $C_{\mathrm{g}}^{i}$ represent (in $\mu \mathrm{g} \mathrm{m}^{-3}$ ) the concentration of species $i$ in the particulate and gas phases, respectively; $H_{i}$ is the Henry's law constant (in Matm ${ }^{-1}$ ); $R$ is the ideal gas law constant; $T$ is the temperature; and $L$ is the liquid water content (LWC) of the aerosol (in $\mathrm{cm}^{3}$ liquid water per $\mathrm{cm}^{3}$ air). We set the liquid water content value within the $10^{-11}-10^{-12}$ range of values proposed by Engelhart et al. (2011) for a deliquescent aerosol.

For a dry aerosol we used an equation similar to Eq. (3), which has been shown to apply equally to the organic compounds that condense into an organic phase (Eq. 4) (e.g., Donahue et al., 2009; Valorso et al., 2011). There, $M_{w}$ stands for the mean organic aerosol molar mass (set to $250 \mathrm{~g} \mathrm{~mol}^{-1}$ based on Robinson et al., 2007), $C_{\mathrm{OA}}$ represents the total organic aerosol mass concentration $\left(\mu \mathrm{g} \mathrm{m}^{-3}\right)$ and $P_{\text {vap }}$ is the saturation vapor pressure (atm) and considering an ideal mixture.

$\xi^{i}=\frac{C_{a}^{i}}{C_{a}^{i}+C_{\mathrm{g}}^{i}}=\left(1+\frac{M_{W} P_{\mathrm{vap}}}{C_{\mathrm{OA}} R T} 10^{6}\right)^{-1}$

Figure 3 illustrates the gas-particle partition of the three semi-volatile compounds considered in our work for the two distinct situations. The fraction of the compound present in the particulate phase (represented by $\xi_{i}$ values) is plotted as a function of $K_{\mathrm{H}}$ for a deliquescent aerosol under typical atmospheric liquid water content situations (upper graph), and as a function of $P_{\text {vap }}$ in the case of a dry organic aerosol with $C_{\mathrm{OA}}$ ranging from low $\left(0.1 \mu \mathrm{g} \mathrm{m}^{-3}\right)$ to high $\left(10 \mu \mathrm{g} \mathrm{m}^{-3}\right)$ atmospheric concentrations (lower graph). This figure shows how the magnitude of the condensation process increases with the $K_{\mathrm{H}}$ value (Fig. 3a) and decreases with the saturation vapor pressure (Fig. 3b). To analyze these results, each graph can be split into three parts.

For deliquescent aerosols:

- When the Henry's law constant value is lower than $10^{7} \mathrm{Matm}^{-1}$ (part I) or greater than $10^{13} \mathrm{Matm}^{-1}$ (part III), considering the selected range of LWC values, the equilibrium is either in favor of the gas phase (part I, not significantly present in the aqueous phase) or in favor of the particulate phase (part III, highly soluble compounds), respectively.

- For intermediate $K_{\mathrm{H}}$ values (part II), the mass of the semi-volatile species is shared between the two phases. In this area, partitioning towards the aqueous phase is an increasing function of LWC values.

Similarly, for dry aerosols:

- The partition is completely in favor of the aerosol phase (low volatility compounds - part 1 ) or towards the gas phase (volatile compounds - part 3) whether the $C_{\mathrm{OA}}$ for saturation vapor pressures are lower than $10^{-13} \mathrm{~atm}$ or greater than $10^{-6}$ atm, respectively.

- For intermediate values (part 2, shaded area), partitioning towards the condensed phase increases with increasing $C_{\mathrm{OA}}$.

The main conclusions that can be drawn from these graphs are the following. First, over this set of atmospheric situations, and whatever the nature of the aerosol - BiA0D never contributes significantly to $\mathrm{OA}$ formation. Indeed, $\xi_{\mathrm{BiA} 0 \mathrm{D}}$ values reach a maximum of $0.3 \%$ in the most favorable combination (dry aerosol, $C_{\mathrm{OA}}=10 \mu \mathrm{g} \mathrm{m}^{-3}$ ). Second, $\xi_{\text {BiAlD }}$ and $\xi_{\mathrm{BiA} 2 \mathrm{D}}$ values respectively range from 1.7 to $14.4 \%$ and from 1.5 to $12.9 \%$ for a deliquescent aerosol, and span the 

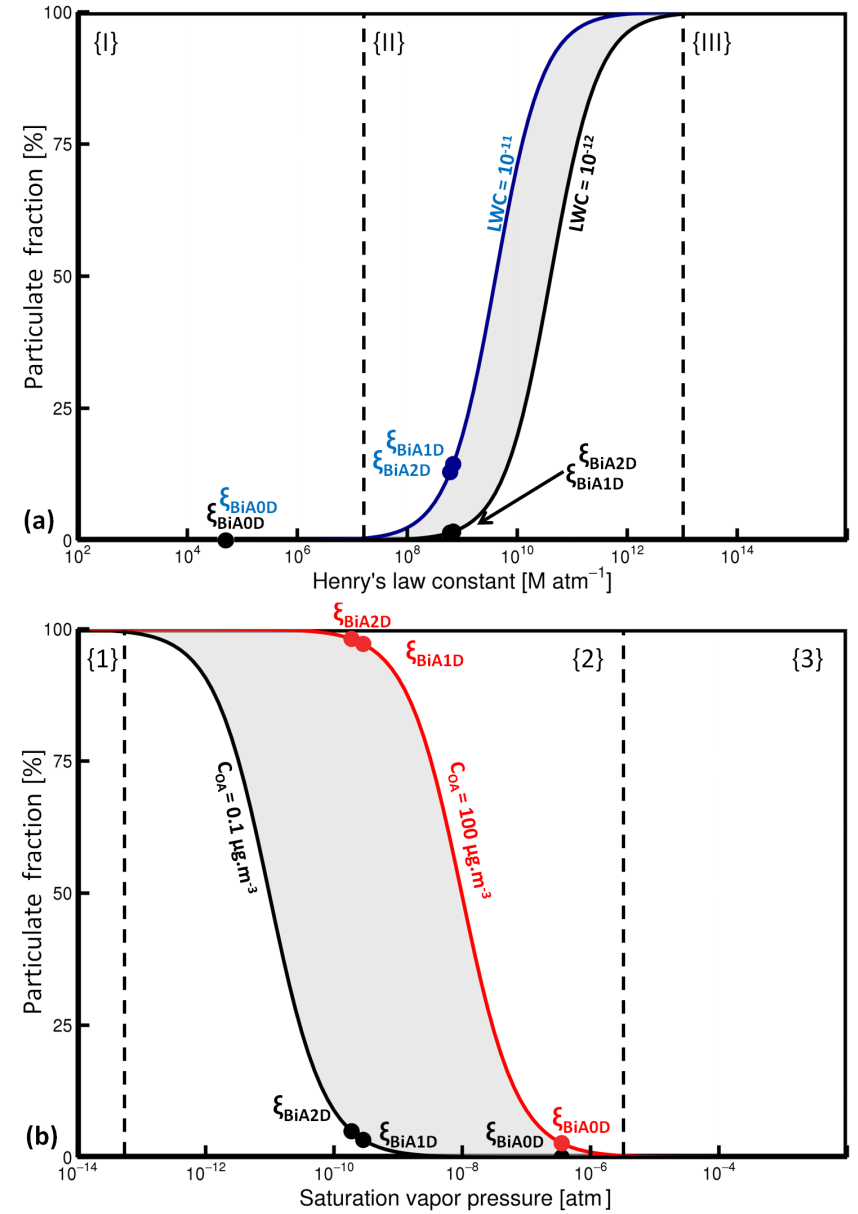

Figure 3. Particulate fraction as a function of Henry's law constant (a) and as a function of saturation vapor pressure (b). The partition of each surrogate is represented by the colored dots for different conditions of organic aerosol mass concentration. Shaded areas represent the range of typical atmospheric condition.

$3.3-77.4 \%$ and the $4.9-83.9 \%$ ranges in the presence of a dry aerosol. Thus, BiA1D and BiA2D are likely to sweep a wide range of partitioning states in the presence of a dry aerosol, while their $K_{\mathrm{H}}$ value are too low to account for a substantial transfer to the aqueous aerosol phase in the presence of a deliquescent aerosol. One should note, however, that in the dry aerosol model (Eq. 4), the activity coefficients are assumed to be unity; in other words, one does not account for interactions among organic species. Since hydrophobic and hydrophilic species have significantly different molecular structures, one could anticipate that including the activity coefficients in the model would reduce the absorption of the hydrophilic species in the hydrophobic organic phase or even lead to the formation of a separate organic phase (Couvidat and Sartelet, 2015). Therefore, the values given for the partition of hydrophilic aerosol should be seen as upper limits. Considering those two elements, $K_{\mathrm{H}}$ appears to be an influential parameter for $\mathrm{BiA}^{*} \mathrm{D}$ species, its modulation - with re- gard to the effective solubility of the surrogates - being likely to strongly enhance the oligomer production efficiency when the aerosol is deliquescent and when the residual gas fraction of the surrogate is not negligible. A species such as BiA0D, which currently remains mostly gaseous in the standard version of the model, may thus be particularly sensitive to the reference value of its Henry's law partitioning constant.

It is thus important to determine how uncertainties in the $K_{\mathrm{H}}$ value influence the results and efficiency of the two oligomer production approaches. For this purpose, we conducted sensitivity tests to the refinement of the most uncertain $K_{\mathrm{H}}$ values, taking into account the structure of the model species and of its components.

\subsubsection{Oligomer production from the oxidation of monoterpenes}

CHIMERE simulations were launched in the reference, KIN, and KPH configurations (both modes) for the two periods of interest defined above. The quantitative differences in the concentrations of the simulated biogenic oligomers, as well as their spatial and temporal features, were investigated. As mentioned previously, we focused on the comparison between the BiOLG (KIN approach) and the

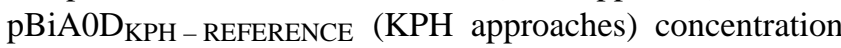
fields.

Figure 4 presents the oligomer daily concentration maxima simulated by CHIMERE from the oxidation of monoterpenes for both parameterizations and for 1 representative day of the simulated period. It highlights large differences in the oligomer concentration fields produced in each approach, both in terms of intensity and spatial distribution. Indeed we can see that, using the KIN approach, the highest oligomer concentrations reach about $0.80 \mu \mathrm{g} \mathrm{m}^{-3}$ over southeastern Europe (Fig. 4a) while in both KPH configurations the peak values are highly localized (not necessary in the same areas according to the mode used) and may exceed $1 \mu \mathrm{g} \mathrm{m}^{-3}$ (Fig. $4 \mathrm{~b}$ and c), with local peaks around $1.50 \mu \mathrm{g} \mathrm{m}^{-3}$ (not visible on the color scale). The same divergences between the $\mathrm{KIN}$ and the KPH model configurations are observed for every day of the summer period, with daily concentration maxima spanning the $0.30-1 \mu \mathrm{g} \mathrm{m}^{-3}$ and the $0.80-2.50 \mu \mathrm{g} \mathrm{m}^{-3}$ ranges, respectively. In terms of hourly peaks, we can learn from the KPH results that there are areas of high gaseous precursor concentrations where BiA0D solubility is (at least transiently) strongly enhanced by local reductions in $\mathrm{pH}$. According to Fig. 3 the decline in $\mathrm{pH}$ has to be greater than 3 or 4 units, with regard to the reference value of 6 , so as to increase the BiA0D partitioning constant by several orders of magnitude and allow the massive transfer of the species to the particulate phase. Such conditions appear to be met off the eastern Italian and notably over well-delimited forested continental areas of northern Spain. From the elevated peak values, it seems likely that the formation of oligomers proceeds by rapid changes in the BiA0D partitioning. In return, 

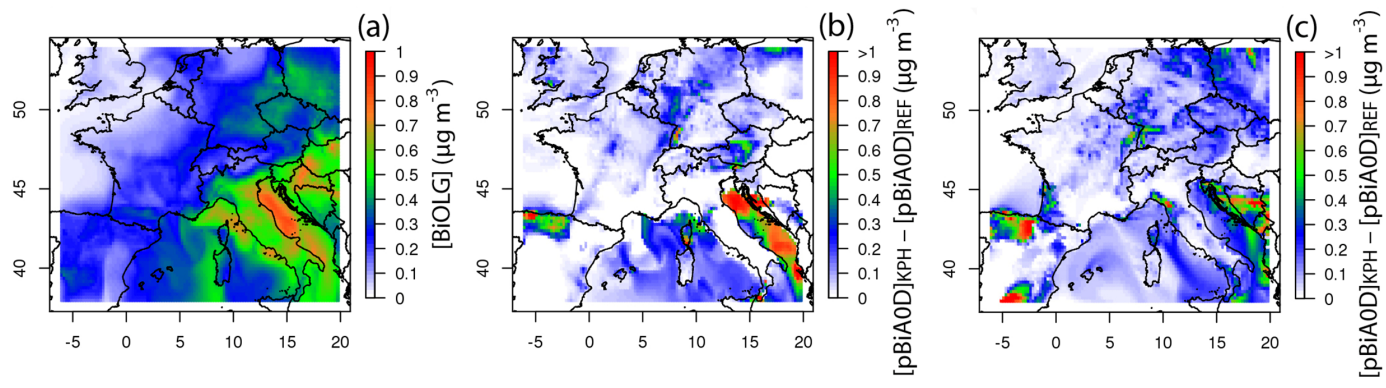

Figure 4. Oligomer daily maxima modeled with the two modeling approaches, using three different CHIMERE configurations for oligomer formation: KIN (a), KPH deliquescent (b) and KPH metastable (c) for 24 July 2006.

the inhomogeneity of oligomer concentration fields suggests a recurring evaporation of the particulate aerosol component in the deliquescent mode and/or the instability of low $\mathrm{pH}$ values. As for the KIN approach, we can see that the time required for the kinetic process, as well as the irreversible nature of the coded process, allows for the presence of large regional oligomer plumes with smooth concentration gradients, as well as the presence of significant numbers of this species over the entire domain.

When averaging our results over the whole summer period, we observe no significant change in the location of high oligomer concentrations, though concentration values are logically lower than hourly peaks, and concentration fields show smoother gradients (Fig. 5). However what is interesting is that the quantitative trends differ from those predicted previously. Indeed, the KIN parameterization produces the highest average oligomer concentrations that range from 0.1 to $0.4 \mu \mathrm{g} \mathrm{m}^{-3}$ over most of the simulation domain. This approach forms well-mixed secondary plumes similar to those of other long-lived atmospheric oxidants such as ozone, with maxima over central Europe and Mediterranean areas. On the contrary, KPH oligomers only slightly exceed $0.1 \mu \mathrm{g} \mathrm{m}^{-3}$ (in both deliquescent and metastable modes), except over small regions of the Adriatic Sea and over northern Spain areas where they reach a value $0.3 \mu \mathrm{g} \mathrm{m}^{-3}$ in the deliquescent mode. It is noticeable that, due to the persistence of an aqueous phase, the metastable mode produces higher oligomer concentrations over the entire domain. However, the difference remains moderate in terms of absolute mass concentration. This feature confirms the lack of oligomer mass accumulation in the KPH approach that was observed in the spatial analysis of hourly maps. It indicates that, beyond the question of relative humidity, favorable conditions for oligomers production in the KPH approach are not often met along time. The conditions of the process reversibility thus have to be more precisely identified and understood, for both modes of this approach.

\subsubsection{Driving parameters of both approaches}

We explored these differences in order to identify the parameters driving production, transport and decomposition of oligomers over continental areas for both approaches. First, the parameters describing the aerosol properties together with the BiA0D partition were plotted over the domain and analyzed for a given time step of the simulation. Then we investigated the temporal evolution of the BiA0D partition and oligomer formation at one grid point of the domain in the three CHIMERE configurations.

Figure 6 presents the nature (humid or dry) and the $\mathrm{pH}$ of the aerosol simulated over Europe for 24 July 2006 at 05:00 UTC, in relation to BiA0D concentration fields. The similarity of the aerosol type (dry or humid, Fig. 6a) determined by ISORROPIA and of the oligomer concentration fields (Fig. 6d) indicates that the existence of a deliquescent aerosol is not ensured in all grid cells and proves to be a discriminatory parameter for oligomer production in the simulations. Figure 6 also emphasizes the role of $\mathrm{pH}$ in this process. In northern Spain, significant oligomer formation is observed in the presence of both a wet aerosol and a very acidic aqueous phase ( $\mathrm{pH}$ around 2.5), although this is not a region where the concentrations of BiA0D are high. On the contrary, over Great Britain, where there is no significant oligomer formation, CHIMERE predicts the presence of a deliquescent aerosol, low gaseous BiA0D concentrations and a $\mathrm{pH}$ value around 4 . These results place the $\mathrm{pH}$ threshold for a significant oligomer production from BiA0D at a value comprised between 3 and 4 . Our previous calculations indicate that the fraction of BiA0D in the aerosol phase remains lower than $1 \%$ for a $\mathrm{pH}$ of 4 , but reaches up to $6-39 \%$ for a $\mathrm{pH}$ of 3 , considering a LWC in the $10^{-11}$ to $10^{-12}$ range $\left(\mathrm{cm}^{3}\right.$ water $\left.\mathrm{cm}^{-3}\right)$. This exponential relationship supports the local formation of high oligomers concentration peaks in Fig. 6d, with regards to the conditions shown in Fig. 6a and b. Clearly, although the presence of the precursor is the first requirement for oligomer production, it is not a determining parameter of the structure of oligomer concentration fields. As the modeled $\mathrm{pH}$ strongly impacts the rate and the intensity of oligomer formation, its robustness was 

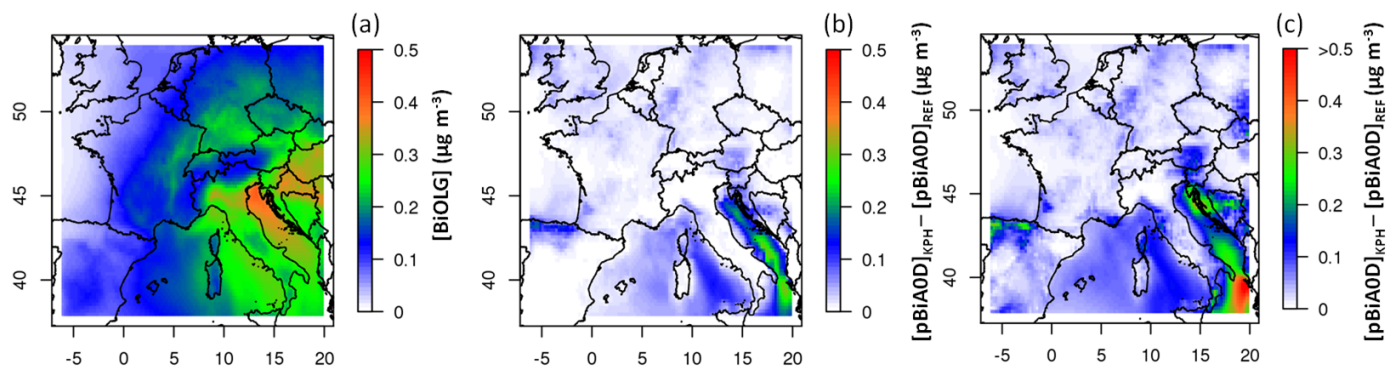

Figure 5. Average modeled oligomer concentration fields from monoterpenes in the KIN (a) and KPH configurations considering both deliquescent (b) and metastable mode (c) for the period of 20 July-3 August 2006.
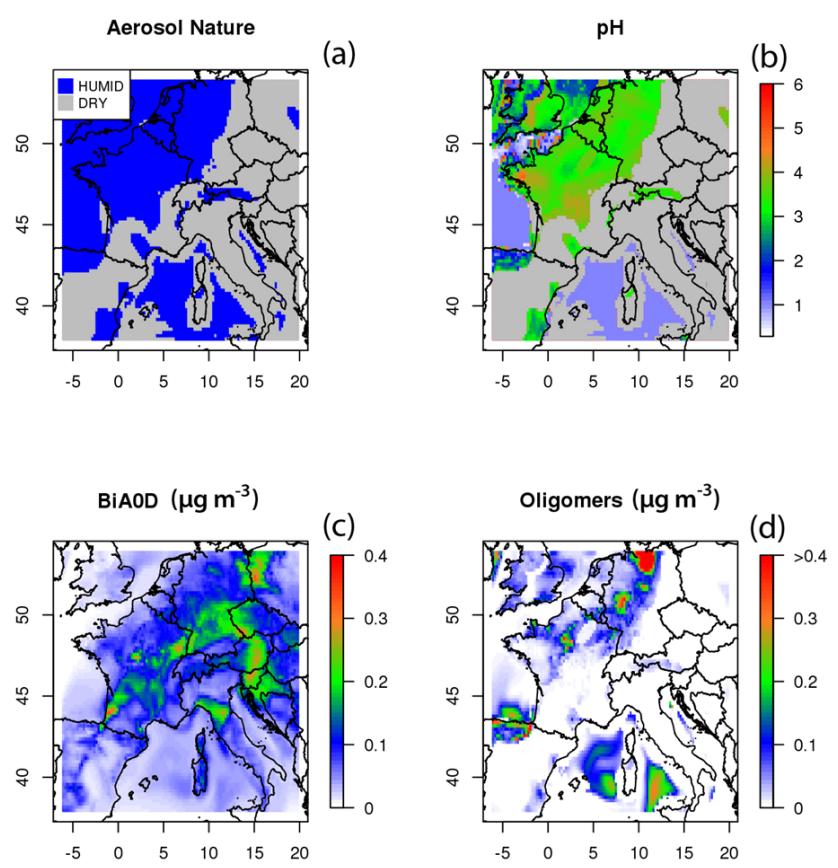

Figure 6. CHIMERE results for 24 July 2006 at 05:00 UTC: nature (humid or dry) of the aerosol (a), $\mathrm{pH}$ of the aqueous phase (b); BiA0D precursor concentration fields in the gas phase for the reference simulation $\left(\mu \mathrm{g} \mathrm{m}^{-3}\right)$ (c) and oligomer concentrations $\left(\mu \mathrm{g} \mathrm{m}^{-3}\right)(\mathbf{d})$ obtained with the KPH approach.

questioned. Although no direct measurements of the $\mathrm{pH}$ of the aerosol have been realized yet, our calculations are consistent with previous experimental studies reporting strongly acidic fine particles (Ludwig and Klemm, 1990; Herrmann, 2003; Keene et al., 2004). Our results are also consistent with the work of Xue et al. (2011), which is based on chemical composition and meteorological data collected at a suburban site in Hong Kong and which estimated the aerosol $\mathrm{pH}$ to range between -1.87 and 3.12. Despite the uncertainty that cannot be fully removed on the modeled $\mathrm{pH}$ value, we did not consider necessary to run other assessment methods, on the basis of the recent works of Henningan et al. (2015), who affirm that thermodynamic models like ISORROPIA are more adapted to estimate the aerosol $\mathrm{pH}$ than proxy methods such as the ones using ion balance and ratios.

In order to address the temporal variation of the aerosol properties related to oligomer formation, concentration time series for BiA0D (reference simulation - blue line) and for oligomers (KIN approach - red line, KPH approach - green line for the deliquescent mode, black line for the metastable mode) have been plotted in Fig. 7 for a given grid cell in northern Spain for the period from 20 to 24 July.

In the KIN approach, BiOLG progressively accumulates in the air mass and shows a smoothed concentration curve along time. Furthermore, oligomer concentrations are not strongly correlated with the presence of gaseous precursors due to the time required for the kinetic formation process. In the $\mathrm{KPH}$ approach, oligomer concentrations are highly variable, showing intense peaks that alternate with periods of nearzero content in the particle phase. It is noted that the black curve (KPH, metastable mode) presents high values on 22 and 23 July that are not observed for the results of the deliquescent mode. These events are neither correlated with a specific origin of the air mass (analysis not shown here) nor with a given BiA0D concentration threshold, but both take place during shaded periods and can therefore be attributed to the limiting effect of a dry aerosol in the deliquescent mode. However, from the co-variability of pBiA0D concentrations in shaded and non-shaded areas, it appears that the existence of a deliquescent aerosol is not the only driving parameter of this formation/evaporation cycle. Indeed, sharp decreases in the particulate fraction of BiA0D are simultaneously observed whatever the aerosol physic state (see 21-22 and 24 July for instance), which implies that $\mathrm{pH}$ variability also plays a decisive role in the calculations, during a large part of the day. During these periods, the $\mathrm{pH}$ value was indeed comprised between 4 and 6 , thus being the principal limitation for BiA0D storage in the particulate phase. Thereby, whatever the selected mode (deliquescent or metastable), there is no continental transport of oligomers due to fast and quantitative release processes. It results in the simulation of short duration peaks, accounting for local production from emissions. 


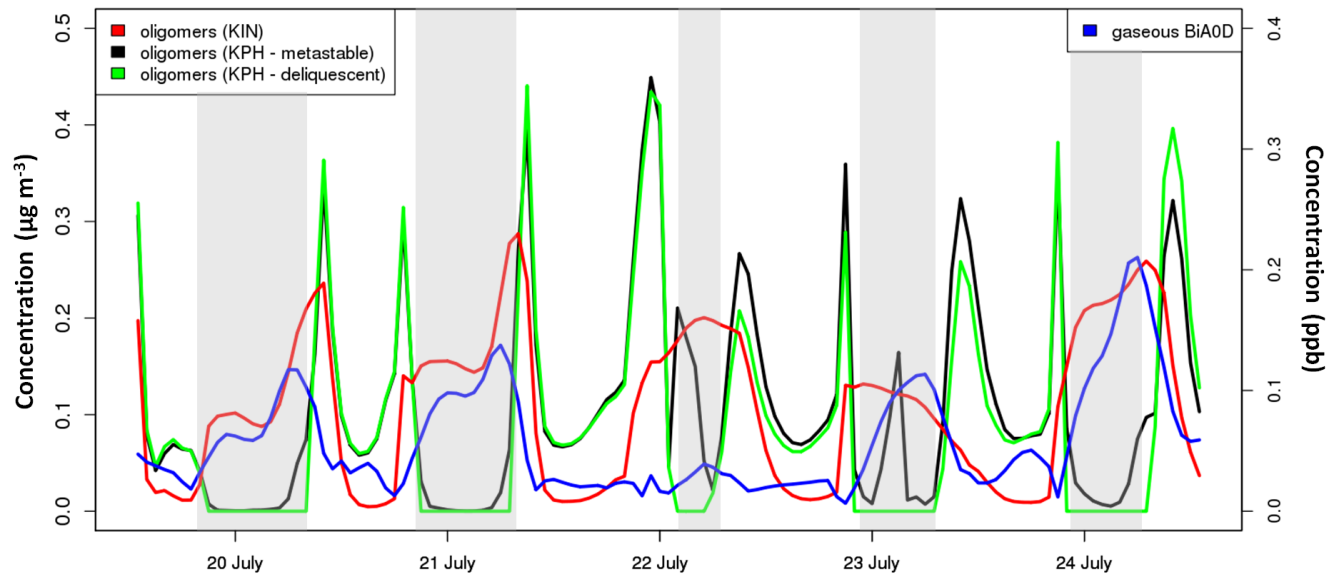

Figure 7. Time series of BiA0D concentrations (ppb) in the reference simulation (blue line), the KIN (red line) oligomer concentrations $\left(\mu \mathrm{g} \mathrm{m}^{-3}\right)$, and the KPH oligomer concentrations $\left(\mu \mathrm{g} \mathrm{m}^{-3}\right)$ in the deliquescent mode (green line) and in the metastable mode (black line), as simulated with CHIMERE for the 20-24 July 2006 period in northern Spain. The shaded areas correspond to the presence of a dry aerosol in the deliquescent configuration.

Finally, Fig. 7 reveals the recurrent loss of particulate BiA0D in northern Spain during the period of study, mostly during daytime periods. It shows an average duration of 2 to $6 \mathrm{~h}$ for the oligomer peak events, which is quite short in view of the time required for pollutant mixing and transport in the troposphere. Therefore, these local phenomena cannot affect PM mixing ratios over large areas and for extended time periods. As the transfer of $\mathrm{BiA0D}$ to the gas phase from the aerosol is frequent and total in the KPH approach, its consistency has to be considered. This process appears to be highly dependent both on the $\mathrm{pH}$ variability - which has been poorly measured up to now - and on the $K_{\mathrm{H}}$ change (from Eq. 1) required to significantly alter the partition of BiA0D between the two phases. That is, the choice of the reference $K_{\mathrm{H}}$ value may be of primary importance. Such findings question the relevance of simulating a low-constrained reversibility for the formation of oligomers in 3-D models.

From these results, three key points can be inferred. First, the structure of oligomer concentration fields is driven both by the kinetic constant rate and by average $\mathrm{pBiA}^{*} \mathrm{D}$ concentrations in the KIN approach, while it mainly depends on the physical and chemical aerosol properties in the KPH approach. In that latter approach, the formation of large quantities of oligomers appears to be conditional on the presence of a deliquescent aerosol and of strong acidity, sufficient initial particulate material, and possibly high radical levels for the oxidation of biogenic VOCs. However, most of the differences between this equilibrium approach and the kinetic one may be reduced by considering a greater stability (better constrained reversibility) in the $\mathrm{pH}$-dependent oligomerization process. The relevance of taking this into consideration in 3-D models will be discussed in the last part of this article. Second, the total mass of simulated oligomers, as well as their participation in the organic fraction of the aerosol, is clearly specific to the adopted approach. This is quantitatively described in Sect. 3.1.4. Finally, we have shown that the default solubility to BiA0D is a determining element of the model results in the KPH approach. As it affects the default quantities of BiA0D (and other oligomer precursors) in the aerosol, it may also play a major role in the results of the KIN approach. As the allocation of this parameter is quite uncertain, the sensitivity of the model results to $K_{\mathrm{H}}$ will be investigated in Sect. 3.2.

\subsubsection{Oligomer to organic aerosol ratio in summer}

In a second step, we estimated the contribution of the modeled oligomers to the biogenic secondary organic aerosol (BSOA) budget. For this analysis, we first considered the ratio of oligomers arising from monoterpenes only to the so-called $\mathrm{BSOA}_{\text {terp }}$ (fraction of SOA induced by both hydrophilic and hydrophobic species from monoterpenes, Fig. 8) and then, using the KIN approach only, all biogenic (isoprene included) oligomers (Fig. 9) and total BSOA.

When considering monoterpenes as the only oligomer precursors, the implementation of a kinetic approach (Fig. 8a and b) results in a significant increase $\left(+1-2 \mu \mathrm{g} \mathrm{m}^{-3}\right)$ of the average OA mass concentration inside the plume. Although the general structure of the plumes is not changed, the kinetic production of oligomers leads to the presence of significant $\mathrm{BSOA}_{\text {terp }}$ values over an area that is much broader than in the reference case. On the opposite, the KPH approach in deliquescent mode (Fig. 8c) does not modify the average mass concentration and spatial distribution of $\mathrm{BSOA}_{\text {terp }}$. The same conclusion can be drawn from the metastable version of KPH (not shown here). In terms of ratios, the OA fraction that remains under the form of oligomers (Fig. 8d and e, representing pOLG to $\mathrm{BSOA}_{\text {terp }}$ ratio) represents 20 to $50 \%$ of the organic aerosol mass originating in monoterpenes over 

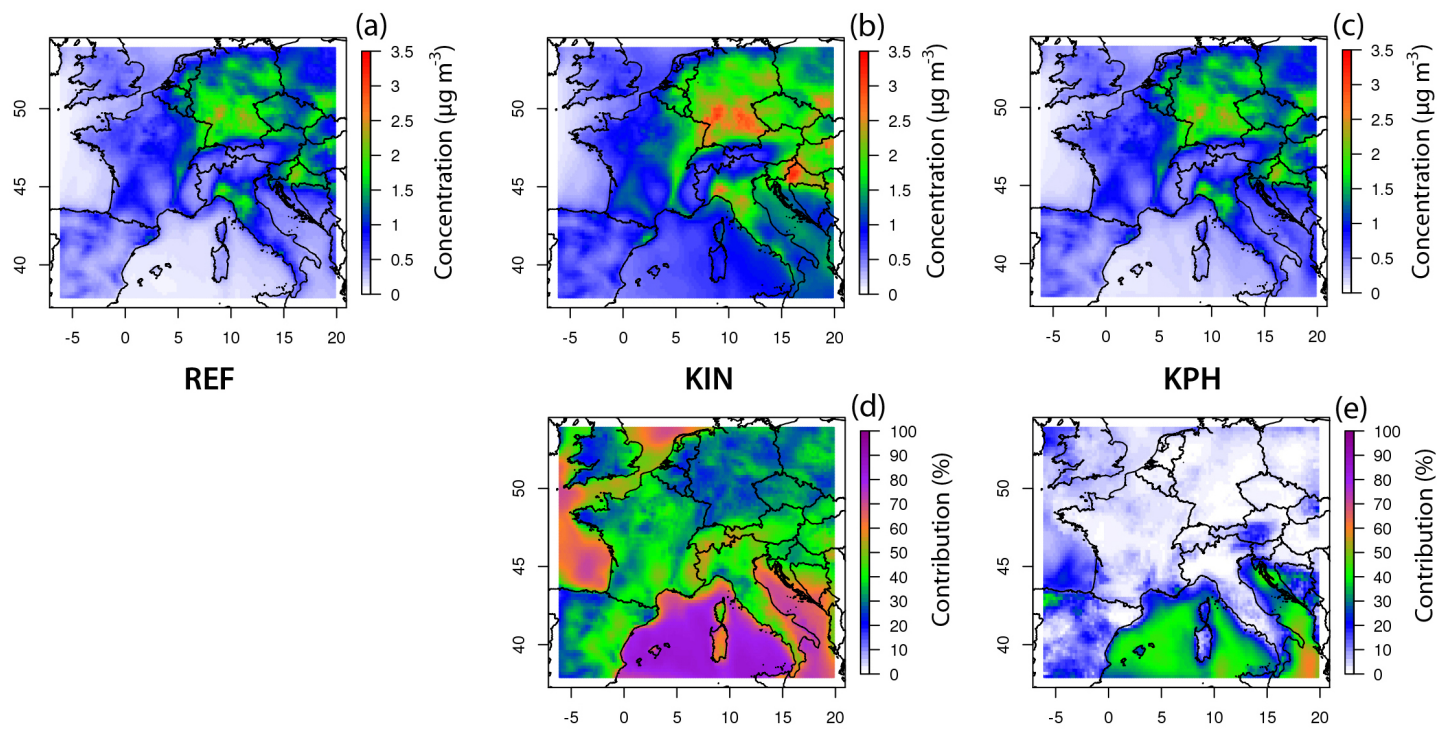

Figure 8. Modeled average BSOA concentration from monoterpenes simulated in the reference case (left), from the KIN approach (center) and from the KPH approach in the metastable mode (right) for the period 20 July-3 August 2006. Lower graph: contribution of oligomers to BSOA $_{\text {terp. }}$.
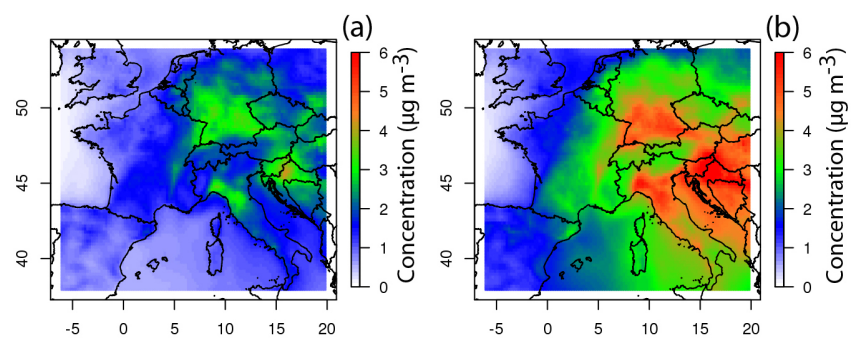

Figure 9. Modeled average BSOA concentration from isoprene and monoterpenes in the reference case (a) and from the KIN approach (b) for the period 20 July-3 August 2006.

all the continental areas in the KIN approach. It is due to the stabilization of a very large proportion of biogenic organic species in the condensed phase under the form of oligomers. However, extreme values of this ratio are simulated over marine areas (see the purple color, meaning that approximately $80 \%$ of $\mathrm{BSOA}_{\text {terp }}$ is under the form of oligomers). This phenomenon can be explained by a combination of two factors. First, irreversible and continuous oligomer formation is the only possible chemical evolution pathway for condensed biogenic species in this version of the model. Second, in our model, marine areas are very little influenced by fresh organic emissions, which tend to favor the omnipresence of an aged OA over the sea. This is probably wrong, as high contributions of primary organic matter to the marine aerosol were predicted. However, they are not taken into account in our simulations (Ovadnevaite et al., 2011). Furthermore, such a high degree of OA conversion to oligomers has never been reported in the literature. Although it is limited on that point, it may be partly unrealistic to simulate a single fate for all biogenic organics present in the particulate phase. Despite this statement, the absolute OA concentration simulated over the sea remains low $\left(<0.2 \mu \mathrm{g} \mathrm{m}^{-3}\right)$, thereby limiting the impact of this potential bias in the model. With regard to KPH simulations, the model indicates (as expected) a very low average contribution of oligomers to the mass of $\mathrm{BSOA}_{\text {terp }}$ over continental areas, except in the north of Spain - where the contribution of oligomers represents 10 to $20 \%$ of the SOA mass concentration - and over marine areas where it sometimes exceeds $40 \%$. Over continental areas, the oligomer fraction is shown to be insignificant because of the frequent reversal of the formation process due to wide $\mathrm{pH}$ variations (see above).

Isoprene oxidation products are a major contributor (around $50 \%$ in our simulations) to the total SOA mass. Therefore, when their potential for oligomerization is considered in KIN, they significantly contribute to this aged organic fraction. Indeed, as can be seen in Fig. 9, when isoprene surrogates are included in the OA aging process, the average BSOA mass fraction increases by 2 to $4 \mu \mathrm{g} \mathrm{m}^{-3}$ over the entire eastern and southern areas of our domain. In these areas, its total concentrations reach 3 to $6 \mu \mathrm{g} \mathrm{m}^{-3}$. The largest increases are obtained over Italy, as well as over the Mediterranean and Adriatic seas, where the recirculation of continental air masses possibly favors air mass aging under low dispersion conditions.

These results highlight the importance of closer identifying the oxidation products of the main atmospheric biogenic volatile organic compounds (BVOCs), as well as their structure and reactivity. In particular, questions still arise 
about the way the evolution of condensed isoprene derivatives should be represented. Indeed, the assumption of Carlton et al. (2010), which states that the formation of oligomers is driven by a same first-order rate constant whatever the oxidation products, is questionable. First, because this parameterization derives from the evolution of cyclic compounds in chamber experiments, which is the case for $\alpha$ - and $\beta$-pinene, the two most common monoterpenes, but not for isoprene and its derivatives. The oxidation of isoprene by hydroxyl radicals leads to the formation of methyl vinyl ketone and methacrolein (Pandis et al., 1991, Paulot et al., 2009), which in turn produces tetrols and methylglyceric acid (Claeys et al., 2004; Surratt et al., 2006; Kleindienst et al., 2009) that are aliphatic compounds. Although oligomer formation from the oxidation of isoprene has been shown to occur in smog chambers (e.g., Sato et al., 2011; Nguyen et al., 2011a, b; Liu et al., 2012a; Tan et al., 2012; Lin et al., 2014), the oligomer formation process is likely to differ significantly from that from aromatics as measured by Kalberer et al. (2004). Second, since this kinetic constant only stands for an average reactivity, Kalberer et al. (2004), during their experiments, could only observe the fact that $50 \%$ of the total organic mass was conversed to oligomer-like species. Such results cannot establish whether all aromatic compounds have undergone oligomerization following the same pathway or if its evolution was only attributable to a specific set of compounds. Applying this parameterization to a large set of biogenic species may cause an incorrect assessment of the contribution of oligomers to the total SOA budget.

\subsubsection{Comparisons of KIN and KPH approaches with measurements}

As mentioned above, no direct measurement of the oligomer fraction of SOA is available at ground-based measurement stations. However, we can assess the role of oligomer formation processes in improving model-measurement comparisons, knowing that the organic fraction of atmospheric aerosols is usually underestimated by models (Heald et al., 2011). In this section, we present the comparison of CHIMERE organic carbon (OC) mass concentration in the $\mathrm{PM}_{10}$ fraction of aerosols, obtained with four different model configurations (REF, KIN and KPH in both modes) with measurements obtained at two EMEP background sites: the rural stations of Harwell in the United Kingdom $(100 \mathrm{~km}$ west of London) and Melpitz in eastern Germany $(150 \mathrm{~km}$ south of Berlin). Figure 10 presents these comparisons for the period 20 July-3 August 2006, the statistical data (mean bias, $\mathrm{MB}$, normalized mean bias, NMB, root mean square error, RMSE, normalized root mean square error, NRMSE, and correlation coefficient, $R$ ) being given in Table 2 .

Globally, whatever the configuration, the modeled OC is severely underestimated at both stations. Nevertheless, the KIN approach provides an increase in the OC mass concentration of about $1 \mu \mathrm{g} \mathrm{m}^{-3}$, which reduces significantly
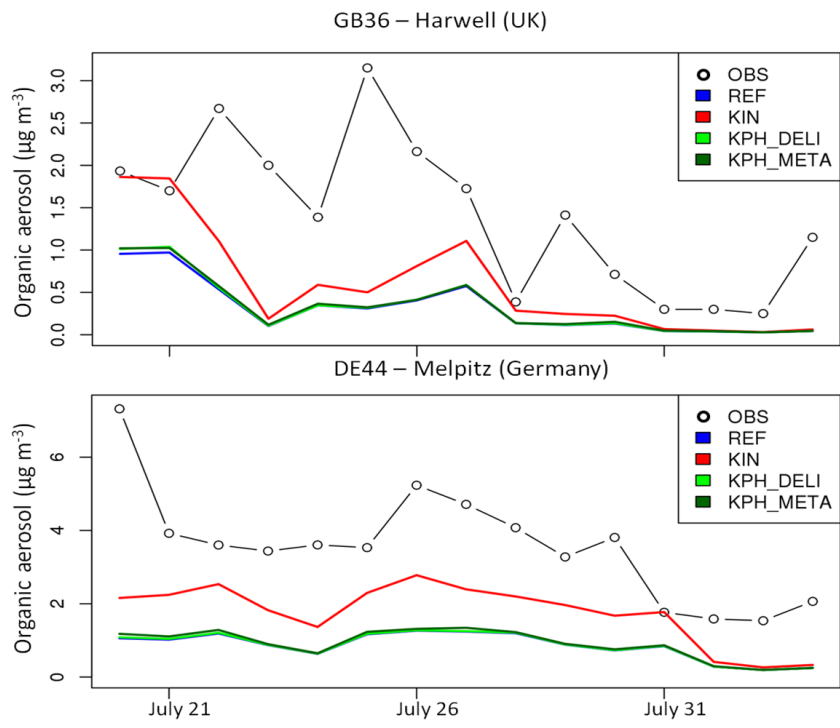

Figure 10. Comparisons of OC measurements (circles) with simulated $\mathrm{OC}$ in $\mathrm{PM}_{10}$ obtained in the reference simulation (blue), using the kinetic approach configuration (red), and using both KPH approaches - either in deliquescent or metastable mode (green and dark-green curves, respectively) at the Harwell (UK, top) and Melpitz (Germany, bottom) sites during the month of July 2006.

the gap between model and measurements, both at Harwell and Melpitz sites. According to Table 2, the mean bias is reduced from -1.10 to $-0.82 \mu \mathrm{g} \mathrm{m}^{-3}$ (Harwell) and from -2.71 to $-1.82 \mu \mathrm{g} \mathrm{m}^{-3}$ (Melpitz) compared with the reference simulation, but the correlation coefficient remains the same (around 0.5 and 0.7, respectively). This is due to the fact that the impact of the kinetic-dependent production of oligomers is quite little time-dependent and thus does not allow for the restitution of the peaks observed along the period and missed by CHIMERE in its reference configuration. Thus, this approach rather provides an increase in the OC background level and does not position oligomers as likely to account for the short-time variability of $\mathrm{OC}$ in summer. This result highlights the importance of ensuring the consistency of the process kinetics, and intensity (which is $K_{\mathrm{H}^{-}}$ dependant).

The $\mathrm{pH}$-dependent approaches have shown to cause a fast and intense production of oligomers that may induce such a short-time variability in the SOA fraction of the aerosol. Here, though, there is no quantitative impact of this process on the OC mass concentration level all along the period, whatever the site. Such results could be expected in the deliquescent configuration, since we concluded that the simulated relative humidity was too low to permit the transport of oligomers over long distances. But it appears that the metastable mode, which promotes oligomer persistence and its transport in the atmosphere, also does not significantly impact the organic carbon concentration at those sites. One possible explanation for the lack of effects is the non-inclusion 
Table 2. Statistical results for organic carbon (OC) simulation (reference, KIN approach, KPH deliquescent and metastable approaches).

\begin{tabular}{lcrrrr}
\hline OC $\left(\mu \mathrm{g} \mathrm{m}^{-3}\right)$ & MB & NMB (\%) & RMSE & NRMSE $(\%)$ & $R$ \\
\hline \multicolumn{7}{c}{ GB36 - Harwell } \\
\hline REF & -1.10 & -77.7 & 1.33 & 94.2 & 0.53 \\
KIN & -0.82 & -57.8 & 1.11 & 78.6 & 0.53 \\
KPH-deliquescent aerosol & -1.09 & -76.8 & 1.32 & 93.5 & 0.52 \\
KPH-metastable aerosol & -1.08 & -76.4 & 1.32 & 93.1 & 0.53 \\
\hline \multicolumn{7}{c}{ DE44 - Melpitz } \\
\hline REF & -2.71 & -76.0 & 3.00 & 83.6 & 0.70 \\
KIN & -1.82 & -51.0 & 2.11 & 59.2 & 0.70 \\
KPH-deliquescent aerosol & -2.70 & -75.7 & 2.97 & 83.3 & 0.70 \\
KPH-metastable aerosol & -2.67 & -74.7 & 2.93 & 82.2 & 0.72 \\
\hline
\end{tabular}

of isoprene as an oligomer precursor in the KPH simulations, especially because the analysis of the model output reveals that 60 to $70 \%$ of KIN oligomers derived from isoprene at both stations. However, the conditions in which the KPH simulation was launched, and mainly the $K_{\mathrm{H}}$ value used for the BiA0D species in conjunction with the variability of the aerosol $\mathrm{pH}$, could also account for the low production of oligomers in remote continental areas of Europe.

The sensitivity of oligomer parameterizations to the $K_{\mathrm{H}}$ input parameters is investigated in the next paragraph.

\subsection{Sensitivity to the $K_{H}$ value}

From the model results presented in Figs. 4 to 7, we found that the amplitude of oligomer formation was potentially strongly dependent on the reference $K_{\mathrm{H}}$ value of BiA0D, whatever approach is taken. Yet, the solubility of Bia0D has to be considered as an uncertain parameter. First because Bia0D accounts for 11 monoterpenes oxidation products, which partition differently and may be poorly approximated via a unique $K_{\mathrm{H}}$ value. Second, it is recognized that, regardless of the group contribution approach used, uncertainties in the estimation of $K_{\mathrm{H}}$ grow when solubility exceeds $10^{4} \mathrm{Matm}^{-1}$, due to a lack of experimental measurements (Raventos-Duran et al., 2010). This is an important issue as all 11 species represented by pinonaldehyde all have a solubility greater than that of pinonaldehyde itself $\left(K_{\mathrm{H}}=4.97 \times\right.$ $\left.10^{4} \mathrm{Matm}^{-1}\right)$. This is notably the case of hydroxypinonaldehyde $\left(K_{\mathrm{H}}=3.26 \times 10^{7} \mathrm{Matm}^{-1}\right)$, ketolimonoaldehyde $\left(K_{\mathrm{H}}=1.7 \times 10^{8} \mathrm{Matm}^{-1}\right)$ or 2-hydroxy-3-iso-propyl-6-oxoheptanal $\left(K_{\mathrm{H}}=2.5 \times 10^{6} \mathrm{Matm}^{-1}\right)$. Consequently, it appears warranted to consider the possibility for the BiA0D Henry's law constant to vary by several orders of magnitude. Thus, in order to evaluate the robustness of each approach to this input parameter, sensitivity tests to the solubility of the BiA0D species were conducted with CHIMERE.

\subsubsection{Influence on the surrogate partitioning properties}

In view of surrogate properties presented in Fig. 3a, our sensitivity study focused on the transition area, that is the $4 \times 10^{8}-4 \times 10^{9} \mathrm{Matm}^{-1}$ range of $K_{\mathrm{H}}$, which allows for accounting for the solubility of all the potential oxidation products mentioned before, while providing estimates of the impact of correcting the global BiA0D $K_{\mathrm{H}}$ value. In this range, we considered three specific $K_{\mathrm{H}}$ values for BiA0D $\left(4.97 \times 10^{4}, 4 \times 10^{8}\right.$ and $\left.4 \times 10^{9} \mathrm{Matm}^{-1}\right)$. Before conducting the sensitivity tests in CHIMERE, we evaluated the influence of $K_{\mathrm{H}}$ on the partitioning coefficient of BiA0D, using the same graphs as in Sect. 2, over the whole range of possible $\mathrm{pH}$ values and with a liquid water content of $10^{-11} \mathrm{~cm}^{3}$ water $\mathrm{cm}^{-3}$. The results are presented in Fig. 11. The reference value $\left(K_{\mathrm{H}}=4.97 \times 10^{4} \mathrm{Matm}^{-1}\right.$, black curve of Fig. 11) corresponds to the left part of Fig. 3a, that is a quite null value of the partitioning coefficient. Here, we can see that only an acidic aqueous phase $(\mathrm{pH}<4)$ allows for the quantitative formation of oligomers. When increasing $K_{\mathrm{H}}$ to a value in the $4 \times 10^{8}$ to $4 \times 10^{9} \mathrm{Matm}^{-1}$ range, we enter the second area of Fig. 3a, where the particulate fraction of BiA0D becomes significant for a LWC of $10^{-11} \mathrm{~cm}^{3}$ water $\mathrm{cm}^{-3}$. There, a significant formation of SOA takes place from neutral conditions with 10 to $52 \%$ of BiA0D being in the condensed phase, depending on the $K_{\mathrm{H}}$ value. For a pH of 5, particulate fraction reaches 48 and $90 \%$ in favor of the aerosol phase, for $K_{\mathrm{H}}=4 \times 10^{8}$ and $4 \times 10^{9} \mathrm{Matm}^{-1}$, respectively. However, in this transition area, the partition of the surrogate species remains strongly influenced by the liquid water content. Such results underline the threshold condensation phenomenon for this range of $K_{\mathrm{H}}$ values. Also, such a sensitivity of BiA0D solubility to the $K_{\mathrm{H}}$ value may have important consequences for the results of the KPH approach (whatever the mode considered). Indeed, considering the highest $K_{\mathrm{H}}$ value instead of the standard one, at $\mathrm{pH}=6$, in the reference simulations, causes the reference particulate fraction of BiA0D to increase from 0 to $52 \%$ (with $L W C=10^{-11} \mathrm{~cm}^{3}$ water $\mathrm{cm}^{-3}$ ). The 


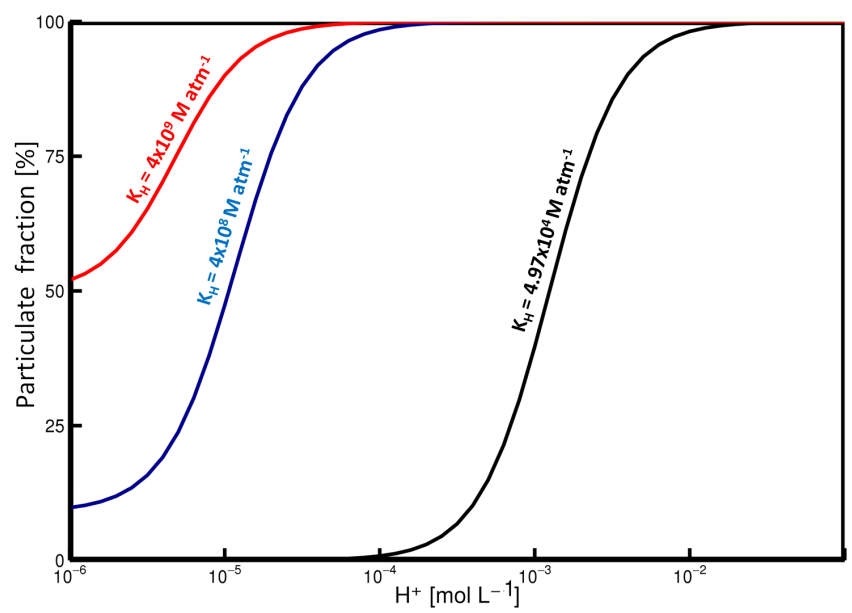

Figure 11. Evolution of the particulate fraction of a given species as a function of $\mathrm{H}^{+}$concentration according to the Eq. (1), for three different values of its Henry's law constant $K_{\mathrm{H}}=\left[4.97 \times 10^{4} ; 4 \times\right.$ $\left.10^{8} ; 4 \times 10^{9} \mathrm{Matm}^{-1}\right]$ at a LWC of $10^{-11} \mathrm{~cm}^{3}$ water $\mathrm{cm}^{-3}$.

impact of implementing a $\mathrm{pH}$-dependent approach will thus be lower and the resulting speciation of the OA material will show a much lesser proportion of oligomers.

\subsubsection{Impact on the simulated oligomer concentration fields}

The sensitivity tests were launched with CHIMERE in the reference, KIN and KPH configurations (in both deliquescent and metastable modes) using each time a different $K_{\mathrm{H}}$ value, as mentioned in the previous section. The average simulated oligomer concentrations fields are shown in Fig. 12 for the KIN (left), KPH deliquescent (center) and KPH metastable (right) approaches.

In the KIN approach, we observe that an increase in the value of the Henry's law constant value (from top to bottom, left column) induces an increase in average simulated oligomer concentrations, due to the low solubility of the BiA0D species in the standard configuration, which was identified as a limiting parameter for the kinetic production of oligomer in the condensed phase. However, this dependency is nonlinear. The increase of $K_{\mathrm{H}}$ by almost 4 orders of magnitude (from $4.97 \times 10^{4}$ to $4 \times 10^{8} \mathrm{Matm}^{-1}$ ) induces approximately the same response as a further increase by 1 order of magnitude (from $4 \times 10^{8}$ to $4 \times 10^{9} \mathrm{Matm}^{-1}$ ), i.e., +0.1 to $+0.2 \mu \mathrm{g} \mathrm{m}^{-3}$ over Italy and the Adriatic Sea in each case. Clearly, there is a low effect of $K_{\mathrm{H}}$ variability under a threshold located around $10^{8}-10^{9} \mathrm{Matm}^{-1}$ in the simulated atmospheric conditions

The interpretation of the model behavior is more complex in the KPH configuration. As stated above, the KPH parameterization affects the partition between the gas and particulate phases, and oligomer concentrations are accounted for by an increment in the quantities of the condensed surro- gate BiA0D. For the deliquescent mode, when $K_{\mathrm{H}}$ is set to $4 \times 10^{8} \mathrm{Matm}^{-1}$ (Fig. 12e), oligomer concentrations increase over continental areas by 0.1 to $0.2 \mu \mathrm{g} \mathrm{m}^{-3}$ on the average, compared with the simulation using the standard $K_{\mathrm{H}}$ value (Fig. $12 \mathrm{~b}$ ). Indeed, as the solubility of Bia0D becomes higher, the decrease in $\mathrm{pH}$ required to form particulate material is reduced. Thus, even for $\mathrm{pH}$ values around $4-5$, the partitioning of BiA0D towards the aerosol phase is favored. In this configuration, the oligomer maxima are located over the continent and not over the Adriatic, which means that the spatial and temporal evolution of SOA is substantially modified by the choice of the default $K_{\mathrm{H}}$ value. When shifting again the $K_{\mathrm{H}}$ value by 1 order of magnitude $\left(4 \times 10^{9} \mathrm{Matm}^{-1}\right.$; Fig. 12h), we observe a decrease in the oligomer concentrations compared with Fig. 12e. This result illustrates the fact that, in this configuration, the default $\mathrm{BiA0D}$ partition is much in favor of the particulate phase, and that there is no significant effect of further increasing the $K_{\mathrm{H}}$ value through Eq. (1). However, in these three simulations, the total SOA mass from hydrophilic biogenic species (not shown, corresponding to pBiA0D dissolved by default + the incremental fraction due to the effect of Eq. 1 on $K_{\mathrm{H}}$ ) increases from the low to the high $K_{\mathrm{H}}$ value scenario. With regard to the metastable mode, the absolute increase in the oligomer concentration due to acidity is significantly higher than in the deliquescent mode (see the concentration scale) due to the fact that, in this configuration, there is no parameter (such as relative humidity, RH) able to set the quantity of oligomer present in the condensed phase back to zero. There, as for the deliquescent mode, the spatial and temporal features of oligomer production are profoundly altered by the assignation of the BiA0D $K_{\mathrm{H}}$ value. Knowing the complex composition of this surrogate species, it is a major difficulty in the implementation of the KPH approach.

Finally, whatever the choice of BiA0D solubility, the location and the spatial extent of oligomer formation remain different in the three configurations of CHIMERE. While the kinetic production of oligomer species leads to a diffuse plume with maximum values in the Mediterranean and over southern Europe, while the highest concentrations are observed over forested areas of central Europe - thus closer to biogenic sources - in the KPH approaches where instantaneous oligomer production is simulated. This result draws our attention to the impact of the oligomer formation rate on the distribution of SOA in continental plumes, especially considering the diversity of relevant SOA precursors in the BiA0D species. Finally, it is worth noting, however, that the high $K_{\mathrm{H}}$ scenario of the metastable KPH mode makes little sense, as the KPH approach is based on the possibility for OA formation to depend on the specificities of the aerosol aqueous phase, which is no longer the case in Fig. 12e and $h$. 

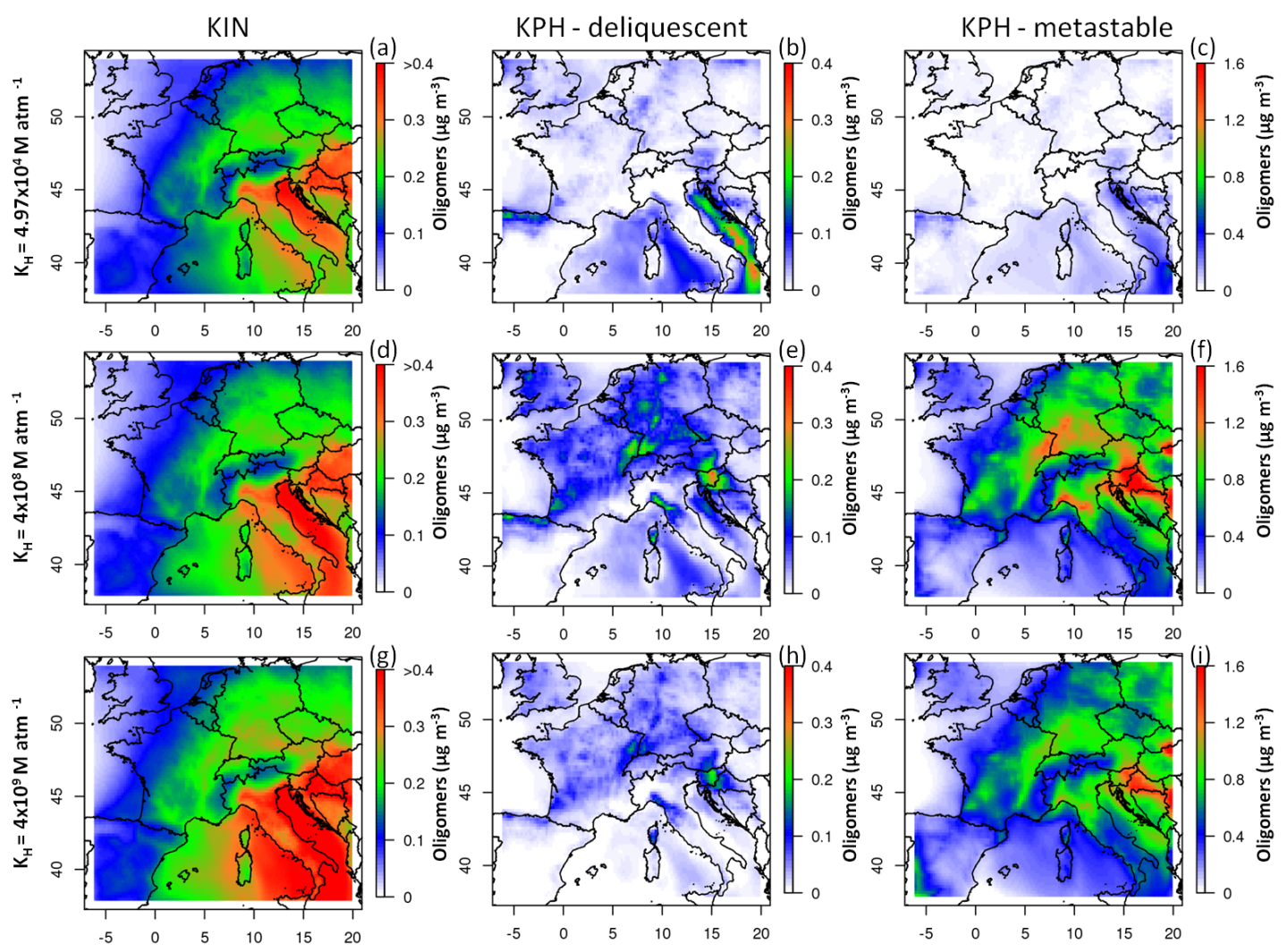

Figure 12. Mean modeled oligomer concentrations from monoterpenes hydrophilic surrogates (thus without BiBmP) for both approaches: KIN (left), KPH deliquescent (center) and KPH metastable mode (right) over 20 July-3 August 2006. The simulations are conducted using for BiA0D the following $K_{\mathrm{H}}$ values: $4.97 \times 10^{4} \mathrm{Matm}^{-1}$ (top, a, b, c), $4 \times 10^{8} \mathrm{Matm}^{-1}$ (middle, d, e, f) and $4 \times 10^{9} \mathrm{Matm}^{-1}$ (bottom, $\mathbf{g}, \mathbf{h}$, i).

\section{Discussions and conclusions}

Given the dissimilarities between the oligomer concentration fields simulated with CHIMERE using two different approaches, and considering the sensitivity tests that were conducted, the principles that guide the different approaches must be discussed, and further developments have to be considered.

\subsection{Oligomer formation from isoprene}

First of all, the fate of isoprene in the condensed phase shall be examined, as isoprene has been recognized as a major SOA precursor through its first generation products methacrolein (MACR) and methyl vinyl ketone (MVK) (Pandis et al., 1991; Carlton et al., 2009), which were found to be important oligomer precursors in the condensed phase (El Haddad et al., 2009; Liu et al., 2012b; Renard et al., 2013). On this specific point, the study of Renard et al. (2015), based on the photo-oxidation of MVK into a photo-reactor, revealed that considering only a first-order rate constant to represent the formation of oligomers is not appropriate, as the oxidation of MVK by $\mathrm{OH}$ was (in the condensed phase of the deliquescent aerosol) governed by a kinetic competition between functionalization and oligomerization, which depends on the precursor initial concentration. Furthermore, the branching ratio in favor of highly oxidized monomers seems to be more important in the condensed phase than in the gas phase (Kroll and Seinfeld, 2008), thus favoring the formation of a stable OA. A multiphase box model study conducted by Ervens et al. (2015) based on the laboratory experiments of Renard et al. (2015) underlined a potential key role of the MVK-to-oxygen concentration ratio in the oligomerization rate under atmospherically relevant conditions. Thus, in the case of isoprene, the formation of oligomers via the oxidation by $\mathrm{OH}_{(\mathrm{aq})}$ in the condensed phase may well be represented by a kinetic approach based on a second-order rate constant. The authors propose a $k_{\text {oligo }}$ of $2.50 \times 10^{-12}$ molec cm ${ }^{-3} \mathrm{~s}^{-1}$ for the single oxidation reaction of MVK and MACR by $\mathrm{OH}_{(\mathrm{aq})}$, but they recommend being cautious with this value as the kinetics may differ within the variety of atmospheric conditions $\left(\mathrm{LWC}, \mathrm{OH}_{(\mathrm{aq})}\right.$, MACR, MVK concentrations, etc.). 


\subsection{Further developments for oligomer formation dynamics}

On a broader level, the difficulty of restituting faithfully oligomer yields and SOA formation dynamics comes from the diversity of the phenomena that drive SOA formation in the atmosphere. It is indeed clear now that oligomerization processes, which may produce up to $50 \%$ of SOA on average, rely on both the volatility of the multiple SVOCs and their reactivity in the condensed phase, which is controlled by a series of oxidation, association and fragmentation reactions that can be kinetically described.

One important issue is thus our ability to describe in an appropriate manner the variety of SVOC behaviors in the gas and condensed phase in an AQM. As for $K_{\mathrm{H}}$ values, we have discussed the fact that the representation of SVOC partitioning in models for now is not highly accurate. Most 3-D models indeed use one single $K_{\mathrm{H}}$ value to account for the behavior of a complex mixture of SOA precursors, and this format clearly prevents the model to restitute the full diversity of the gas-particle partitioning of individual compounds in time and space. This is all the more important because the results we obtained with CHIMERE showed that oligomer concentrations present a considerable sensitivity to the $K_{\mathrm{H}}$ value selected for the biogenic surrogate species that produces SOA. Similarly, when simulating chemistry in the aerosol phase, the allocation of distinct kinetic constant values for the reactivity of the condensed oligomer precursors would be valuable. Kalberer et al. (2006) effectively observed disparities in the temporal evolution of the aerosol molar mass while studying the oxidation of trimethylbenzene, $\alpha$-pinene and isoprene. Taking this into account would probably have increased the OC short-time variability of the KIN method. However, increasing the degree of refinement of a modeling approach through a differentiation of individual behaviors is not always a good solution. The more refined the scheme becomes, the more difficult it is to collect the details about organic compound reactivity, making it difficult to set up the approach in a 3-D model. As an example, the $\mathrm{KPH}$ approach proposes to consider the specific formation of oligomers from the polymerization of aldehydes only, which may happen through diverse acid-catalyzed reactions. Although it is evident that the consideration of only one single polymerization pathway constitutes a limitation for the quantitative simulation of SOA production from ambient organic precursors, this hypothesis has the advantage of proposing a well-identified process, which can be adjusted in the model in terms of intensity, and upon the environmental conditions, from experimental knowledge about this reaction. However, in this approach, isoprene oxidation products (ISOPA) could not be considered as oligomer precursors, due to the fact that the KPH approach is only applicable to aldehydes and that there is no detail about the structural properties of the ISOPA surrogate species in the current CHIMERE chemical scheme. Including all or part of this species in the oligomer- ization process would thus have introduced an indeterminate uncertainty in our simulations. The outcome of this is a severe underestimation of the modeled OC compared with Harwell and Melptiz observation, that was - at least partly - attributed to the non-inclusion of isoprene in oligomer precursors when running CHIMERE with the KPH configuration. Similarly, we have seen that the dependence of the model results upon (i) the state (deliquescent or metastable) of the aerosol, and (ii) its inorganic composition and $\mathrm{pH}$, constitute a key challenge for the implementation of the KPH approach. In this respect, there is a necessity to define a parameterization focusing on the restitution of a unique parameter (such as the dynamics of global SOA yields), and relying on an irreducible set of parameters and processes, provided that it allows the model to perform satisfactorily with regard to existing measurements. For this purpose, in situ atmospheric oligomer measurements conducted at various distances from the sources would be absolutely necessary to assign a representative average value for the $K_{\mathrm{H}}$ of the SVOC surrogate species - as our results showed that the rate and intensity of the SVOC transfer to the aerosol phase give the SOA plumes their shapes.

Another path of research would be to impose a minimum value for the transfer of a given biogenic SVOC species to the aqueous phase, in order to quantitatively restitute rapid oligomer formation without significantly increasing the size of the chemical scheme in the AQM. Then, kinetically adjusted chemical reactions simulating both the oligomer formation and release should be added to control the stability of this organic fraction in the aerosol. Indeed, the definitive character of the formation of oligomers is the key to a correct representation of their total mass and dynamics of formation, as was shown by our comparative study of irreversible (KIN) and reversible (KPH) oligomerization processes at the continental scale.

How can we improve the representation of oligomer stability in the modeling approaches investigated here? The literature does not give a straightforward answer to the question of oligomerization reversibility. Several observations and experiments reported in the literature point to the irreversibility - at least partial - of the oligomerization process. According to a recent study of Liu et al. (2012b), the formation of oligomers from methacrolein and methyl vinyl ketone (isoprene oxidation products) is irreversible. This assumption is supported by the recent works of Hall and Johnston (2012a), who investigated the thermal stability of a SOA matrix including $50 \%$ of oligomeric species formed by the ozonolysis of $\alpha$-pinene: the authors concluded that, at ambient temperatures, oligomeric species should be non-volatile by structure. However, Trump and Donahue (2014) report discording results about SOA mass yields in these experiments, that point to an oligomerization process that would be reversible under specific conditions (dilution, temperature), which is probably a good compromise in the interpretation of all laboratory experiments. 
Considering these elements, the kinetic approach that represents oligomer formation as the only possible fate for the relevant condensed organics may lead to a significant overestimation of the oligomer fraction in the aerosol. Thus, it should at least take into account a possible loss of SOA by evaporation, due notably to fragmentation processes (Renard et al., 2015). Indeed, organic compounds in the particulate phase have shown to be submitted to a variety of non-oxidative and oxidative reactions leading to the formation of both semi-volatile and non-volatile compounds, depending on their final molecular weight (Kroll and Seinfeld, 2008; Kroll et al., 2009). Furthermore, the absence of reversibility in the kinetic approach makes it little adaptable to laboratory observations such as the evaporation of SOA from $\alpha$-pinene on the scale of a few hours (Grieshop et al., 2007). On the contrary, the high SOA mass yields obtained from the oxidation of biogenic SVOCs cannot be reproduced using the KPH-deliquescent approach, as SOA formed this way is permanently released due to aerosol water evaporation or $\mathrm{pH}$ increase. Whatever the model configuration, our works have shown that the oligomerization reversibility proposed by the KPH approach was difficult to set up and control in an AQM. Therefore, considering (i) the laboratory experiments conducted by Hall and Johnson (2012b) on the ozonolysis of $\alpha$-pinene, which indicated that oligomer formation would be driven by reactive uptake rather than by the partition of monomers between both phases and (ii) the fact that this reactive uptake may be observed within seconds (Heaton et al., 2007; Hall and Johnson, 2012b), it appears more realistic to propose a representation of the oligomerization process in two stages: a first fast step modifying directly the monomer partitioning so as to represent the rapid formation of oligomers (not permitted by the KIN approach only), and a stabilization step consisting of a kinetic uptake of the OA previously formed (not adjustable in a KPH approach). Trump and Donahue (2014) have recently proposed a comprehensive but simplified vision of reversible oligomerization that effectively combines a partitioning equilibrium and a condensed-phase kinetic reactivity, and that clearly addresses the issue of reversibility. This vision was built from the VBS approach, a modeling technique relying on SVOC volatility bins rather than on identified chemical species to represent the progressive formation of SOA from gaseous organic compounds upon atmospheric oxidation processes (Robinson et al., 2007). The works of Trump and Donahue propose a detailed analysis of an expanded VBS version, taking into account oligomer formation dynamics in a quite similar way as here: namely, the description of the equilibriumphase partitioning of various VOC oxidation products from a given volatility bin, and a kinetic-dependent reactivity in the condensed phase where the association of two identical particulate monomers compete with the dissociation of the dimers thus formed. The ratio of those two rate constants makes a dimerization formation equilibrium. There, major simplifying assumptions are made. They mainly stem from the fact that only one single volatility class of condensed products reacts, and that this class reacts in its entirety - regardless of the structure of precursors - to form carboxylic acid dimers. Indeed, representative equilibrium constants for the dimerization reaction were derived from laboratory works on dicarboxylic acid dimers formation. Finally, it is stressed by the authors that neither of the simplifications considered in this approach is likely to be realistic, and that the stated goal of their work is only to identify what type of chemistry this method produces and how it helps understanding/representing oligomers in the atmosphere. Despite such simplifications, the authors show that their approach allows for restituting experimental SOA yields for different initial OA conditions, as well as SOA formation dynamics. A particularly interesting result of this approach is the simulation of a two-stage SOA evaporation (monomers evaporate rapidly upon dilution while only a modest drop in oligomer concentration is simulated due to the equilibrium dynamics) that may help reproducing recent observations of delayed SOA evaporation. Through sensitivity tests to the condensedphase reactivity kinetics, this approach also outlines that an irreversible oligomerization process (high dimerization to evaporation kinetic ratio) would definitely appear incompatible with the observed SOA mass-yield behaviors.

As for conventional modeling approaches relying on molecule structural properties, and based on these findings, a KPH-like approach considering a further reactive uptake - with partial reversibility or fragmentation so as to fit the observations about the hysteresis of SOA formation and evaporation - could be a suitable parameterization to represent the formation of oligomers from monoterpenes. Even so, the determination of the aerosol mode (deliquescent/metastable) is not an obvious choice. Although Fountoukis et al. (2009) concluded from plume studies that organics could promote thermodynamically stable water down to very low RH, Moya et al. (2002) have shown that considering a metastable mode for $\mathrm{PM}_{1}$ (where organic matter is predominantly present) leads, under low relative humidity conditions $(<60 \%)$, to significant errors in the concentrations of the inorganic species, which indirectly determine the aerosol $\mathrm{pH}$ and thus oligomers formation. Similarly, Mikhailov et al. (2013) found - from the analysis of atmospheric aerosols - that under a RH level of about $70 \%$, organic species may not be completely dissolved in the aqueous phase and may also coexist in a solid aerosol phase. These studies both conclude to the importance of considering a deliquescent mode for low relative humidity conditions.

Beyond the fundamental lack of in situ data required to evaluate oligomer and SOA concentration fields produced by AQMs, new advances are expected from further laboratory works to improve the accuracy of SOA formation processes in the models. In particular, as has been indicated by Trump and Donahue (2014), any sophistication of oligomer formation approaches would require advances in the knowledge of SOA yields and oligomer production dynamics. Such exper- 
iments would allow for building relevant thermodynamical and chemical schemes that simulate the dynamics of SVOC capture, their reactivity in the condensed phase, as well as their further potential for atmospheric release, to be implemented in AQMs.

Acknowledgements. This work was supported by the French national program PRIMEQUAL in the frame of the OLD-AIR project. The authors acknowledge the EBAS data providers and owners for the aerosol measurements at EMEP sites.

Edited by: H. Tost

\section{References}

Aksoyoglu, S., Keller, J., Barmpadimos, I., Oderbolz, D., Lanz, V. A., Prévôt, A. S. H., and Baltensperger, U.: Aerosol modelling in Europe with a focus on Switzerland during summer and winter episodes, Atmos. Chem. Phys., 11, 7355-7373, doi:10.5194/acp11-7355-2011, 2011

Bessagnet, B., Hodzic, A., Vautard, R., Beekmann, M., Cheinet, S., Honore, C., Liousse, C., and Rouil, L.: Aerosol modeling with CHIMERE - preliminary evaluation at the continental scale, Atmos. Environ., 38, 2803-2817, doi:10.1016/j.atmosenv.2004.02.034, 2004.

Bessagnet, B., Menut, L., Curci, G., Hodzic, A., Guillaume, B., Liousse, C., Moukhtar, S., Pun, B., Seigneur, C., and Schulz, M.: Regional modeling of carbonaceous aerosols over Europe-focus on secondary organic aerosols, J. Atmos. Chem., 61, 175-202, doi:10.1007/s10874-009-9129-2, 2008.

Bessagnet, B., Menut, L., Curci, G., Hodzic, A., Guillaume, B., Liousse, C., Moukhtar, S., Pun, B., Seigneur, C., and Schulz, M.: Regional modeling of carbonaceous aerosols over Europe-focus on secondary organic aerosols, J. Atmos. Chem., 61, 175-202, 2009.

Carlton, A. G., Turpin, B. J., Altieri, K. E., Seitzinger, S. P., Mathur, R., Roselle, S. J., and Weber, R. J.: CMAQ Model Performance Enhanced When In-Cloud Secondary Organic Aerosol is Included: Comparisons of Organic Carbon Predictions with Measurements, Environ. Sci. Technol., 42, 87988802, doi:10.1021/es801192n, 2008.

Carlton, A. G., Wiedinmyer, C., and Kroll, J. H.: A review of Secondary Organic Aerosol (SOA) formation from isoprene, Atmos. Chem. Phys., 9, 4987-5005, doi:10.5194/acp-9-4987-2009, 2009.

Carlton, A. G., Bhave, P. V., Napelenok, S. L., Edney, E. D., Sarwar, G., Pinder, R. W., Pouliot, G. A., and Houyoux, M.: Model Representation of Secondary Organic Aerosol in CMAQv4.7, Environ. Sci. Technol., 44, 8553-8560, doi:10.1021/es100636q, 2010.

Carter, W. P. L.: A Detailed Mechanism for the Gas-Phase Atmospheric Reactions of Organic-Compounds, Atmos. Environ. AGen., 24, 481-518, doi:10.1016/0960-1686(90)90005-8, 1990.

Couvidat, F. and Sartelet, K.: The Secondary Organic Aerosol Processor (SOAP v1.0) model: a unified model with different ranges of complexity based on the molecular surrogate approach,
Geosci. Model Dev., 8, 1111-1138, doi:10.5194/gmd-8-11112015, 2015.

Couvidat, F. and Seigneur, C.: Modeling secondary organic aerosol formation from isoprene oxidation under dry and humid conditions, Atmos. Chem. Phys., 11, 893-909, doi:10.5194/acp-11893-2011, 2011

Couvidat, F., Debry, E., Sartelet, K., and Seigneur, C.: A hydrophilic/hydrophobic organic $\left(\mathrm{H}^{2} \mathrm{O}\right)$ aerosol model: Developmentn evaluation and sensitivity analysis, J. Geophys. Res., 117, D10304, doi:10.1029/2011JD017214, 2012.

Claeys, M., Graham, B., Vas, G., Wang, W., Vermeylen, R., Pashynska, V., Cafmeyer, J., Guyon, P., Andreae, M. O., Artaxo, P., and Maenhaut, W.: Formation of Secondary Organic Aerosol Through Photooxidation of Isoprene, Science, 303, 1173-1176, 10.1126/science.1092805, 2004.

Donahue, N. M., Robinson, A. L., and Pandis, S. N.: Atmospheric organic particulate matter: From smoke to secondary organic aerosol, Atmos. Environ., 43, 94-106, 2009.

Dudhia, J.: A nonhydrostatic Version of the Penn State-NCAR Mesoscale Model: Validation Tests and Simulation of an Atlantic Cyclone and Cold Front, Mon. Weather Rev., 121, 1493-1513, 1993.

El Haddad, I., Yao Liu, Nieto-Gligorovski, L., Michaud, V., Temime-Roussel, B., Quivet, E., Marchand, N., Sellegri, K., and Monod, A.: In-cloud processes of methacrolein under simulated conditions - Part 2: Formation of secondary organic aerosol, Atmos. Chem. Phys., 9, 5107-5117, doi:10.5194/acp-9-5107-2009, 2009.

Ervens, B., Turpin, B. J., and Weber, R. J.: Secondary organic aerosol formation in cloud droplets and aqueous particles (aqSOA): a review of laboratory, field and model studies, Atmos. Chem. Phys., 11, 11069-11102, doi:10.5194/acp-1111069-2011, 2011.

Ervens, B., Renard, P., Tlili, S., Ravier, S., Clément, J.-L., and Monod, A.: Aqueous-phase oligomerization of methyl vinyl ketone through photooxidation - Part 2: Development of the chemical mechanism and atmospheric implications, Atmos. Chem. Phys., 15, 9109-9127, doi:10.5194/acp-15-9109-2015, 2015.

Fountoukis, C., Nenes, A., Sullivan, A., Weber, R., Van Reken, T., Fischer, M., Matías, E., Moya, M., Farmer, D., and Cohen, R. C.: Thermodynamic characterization of Mexico City aerosol during MILAGRO 2006, Atmos. Chem. Phys., 9, 2141-2156, doi:10.5194/acp-9-2141-2009, 2009

Fuzzi, S., Andreae, M. O., Huebert, B. J., Kulmala, M., Bond, T. C., Boy, M., Doherty, S. J., Guenther, A., Kanakidou, M., Kawamura, K., Kerminen, V.-M., Lohmann, U., Russell, L. M., and Pöschl, U.: Critical assessment of the current state of scientific knowledge, terminology, and research needs concerning the role of organic aerosols in the atmosphere, climate, and global change, Atmos. Chem. Phys., 6, 2017-2038, doi:10.5194/acp-62017-2006, 2006.

Gao, S., Ng, N. L., Keywood, M., Varutbangkul, V., Bahreini, R., Nenes, A., He, J. W., Yoo, K. Y., Beauchamp, J. L., Hodyss, R. P., Flagan, R. C., and Seinfeld, J. H.: Particle phase acidity and oligomer formation in secondary organic aerosol, Environ. Sci. Technol., 38, 6582-6589, doi:10.1021/es049125k, 2004.

Gelbard, F. and Seinfeld, J. H.: Simulation of Multicomponent Aerosol Dynamics, J. Colloid Interf. Sci., 78, 485-501, doi:10.1016/0021-9797(80)90587-1, 1980. 
Grieshop, A. P., Donahue, N. M., and Robinson, A. L.: Is the gas-particle partitioning in alpha-pinene secondary organic aerosol reversible?, Geophys. Res. Lett., 34, L14810, doi:10.1029/2007GL029987, 2007.

Guenther, A., Karl, T., Harley, P., Wiedinmyer, C., Palmer, P. I., and Geron, C.: Estimates of global terrestrial isoprene emissions using MEGAN (Model of Emissions of Gases and Aerosols from Nature), Atmos. Chem. Phys., 6, 3181-3210, doi:10.5194/acp-63181-2006, 2006.

Hall IV, W. A. and Johnston, M. V.: The Thermal-Stability of Oligomers in Alpha-Pinene Secondary Organic Aerosol, Aerosol Sci. Tech., 46, 983-989, 2012a.

Hall IV, W. A. and Johnston, M.: Oligomer Formation Pathways in Secondary Organic Aerosol from MS and MS/MS Measurements with High Mass Accuracy and Resolving Power, J. Am. Soc. Mass Spectr., 23, 1097-1108, 2012b.

Hauglustaine, D., Hourdin, F., Jourdain, L., Filiberti, M.-A., Walters, S., Lamarque, J.-F., and Holland, E.: Interactive chemistry in the Laboratoire de Météorologie Dynamique general circulation model: Description and background tropospheric chemistry evaluation, J. Geophys. Res.-Atmos., 109, D04314, doi:10.1029/2003JD003957, 2004.

Heald, C. L., Coe, H., Jimenez, J. L., Weber, R. J., Bahreini, R., Middlebrook, A. M., Russell, L. M., Jolleys, M., Fu, T.-M., Allan, J. D., Bower, K. N., Capes, G., Crosier, J., Morgan, W. T., Robinson, N. H., Williams, P. I., Cubison, M. J., DeCarlo, P. F., and Dunlea, E. J.: Exploring the vertical profile of atmospheric organic aerosol: comparing 17 aircraft field campaigns with a global model, Atmos. Chem. Phys., 11, 12673-12696, doi:10.5194/acp-11-12673-2011, 2011.

Heaton, K. J., Dreyfus, M. A., Wang, S., and Johnston, M. V.: Oligomers in the early stage of biogenic secondary organic aerosol formation and growth, Environ. Sci. Technol., 41, 61296136, 2007.

Hennigan, C. J., Izumi, J., Sullivan, A. P., Weber, R. J., and Nenes, A.: A critical evaluation of proxy methods used to estimate the acidity of atmospheric particles, Atmos. Chem. Phys., 15, 27752790, doi:10.5194/acp-15-2775-2015, 2015.

Herrmann, H.: Kinetics of Aqueous Phase Reactions Relevant for Atmospheric Chemistry, Chem. Rev., 103, 4691-4716, 2003.

Jang, M. S., Czoschke, N. M., and Northcross, A. L.: Semiempirical model for organic aerosol growth by acid-catalyzed heterogeneous reactions of organic carbonyls, Environ. Sci. Technol., 39, 164-174, doi:10.1021/es048977h, 2005.

Jimenez, J. L., Canagaratna, M. R., Donahue, N. M., Prevot, A. S. H., Zhang, Q., Kroll, J. H., DeCarlo, P. F., Allan, J. D., Coe, H., Ng, N. L., Aiken, A. C., Docherty, K. S., Ulbrich, I. M., Grieshop, A. P., Robinson, A. L., Duplissy, J., Smith, J. D., Wilson, K. R., Lanz, V. A., Hueglin, C., Sun, Y. L., Tian, J., Laaksonen, A., Raatikainen, T., Rautiainen, J., Vaattovaara, P., Ehn, M., Kulmala, M., Tomlinson, J. M., Collins, D. R., Cubison, M. J., Dunlea, E. J., Huffman, J. A., Onasch, T. B., Alfarra, M. R., Williams, P. I., Bower, K., Kondo, Y., Schneider, J., Drewnick, F., Borrmann, S., Weimer, S., Demerjian, K., Salcedo, D., Cottrell, L., Griffin, R., Takami, A., Miyoshi, T., Hatakeyama, S., Shimono, A., Sun, J. Y., Zhang, Y. M., Dzepina, K., Kimmel, J. R., Sueper, D., Jayne, J. T., Herndon, S. C., Trimborn, A. M., Williams, L. R., Wood, E. C., Middlebrook, A. M., Kolb, C. E., Baltensperger, U., and Worsnop, D. R.: Evolution of Or- ganic Aerosols in the Atmosphere, Science, 326, 1525-1529, doi:10.1126/science.1180353, 2009.

Kalberer, M., Paulsen, D., Sax, M., Steinbacher, M., Dommen, J., Prevot, A. S. H., Fisseha, R., Weingartner, E., Frankevich, V., Zenobi, R., and Baltensperger, U.: Identification of polymers as major components of atmospheric organic aerosols, Science, 303, 1659-1662, doi:10.1126/science.1092185, 2004.

Kalberer, M., Sax, M., and Samburova, V.: Molecular Size Evolution of Oligomers in Organic Aerosols Collected in Urban Atmospheres and Generated in a Smog Chamber, Environ. Sci. Technol., 40, 5917-5922, 2006.

Kanakidou, M., Seinfeld, J. H., Pandis, S. N., Barnes, I., Dentener, F. J., Facchini, M. C., Van Dingenen, R., Ervens, B., Nenes, A., Nielsen, C. J., Swietlicki, E., Putaud, J. P., Balkanski, Y., Fuzzi, S., Horth, J., Moortgat, G. K., Winterhalter, R., Myhre, C. E. L., Tsigaridis, K., Vignati, E., Stephanou, E. G., and Wilson, J.: Organic aerosol and global climate modelling: a review, Atmos. Chem. Phys., 5, 1053-1123, doi:10.5194/acp-5-1053-2005, 2005.

Keene, W. C., Pszenny, A. A. P., Maben, J. R., Stevenson, E., and Wall, A. C. D.: Closure evaluation of size-resolved aerosol pH in the New England coastal atmosphere during summer, J. Geophys. Res.-Atmos., 109, D23307, doi:10.1029/2004JD004801, 2004.

Kleindienst, T. E., Lewandowski, M., Offenberg, J. H., Jaoui, M., and Edney, E. O.: The formation of secondary organic aerosol from the isoprene $+\mathrm{OH}$ reaction in the absence of $\mathrm{NO}_{x}$, Atmos. Chem. Phys., 9, 6541-6558, doi:10.5194/acp-9-6541-2009, 2009.

Kroll, J. H. and Seinfeld, J. H.: Chemistry of secondary organic aerosol: Formation and evolution of low-volatility organics in the atmosphere, Atmos. Environ., 42, 3593-3624, doi:10.1016/j.atmosenv.2008.01.003, 2008.

Kroll, J. H., Ng, N. L., Murphy, S. M., Flagan, R. C., and Seinfeld, J. H.: Secondary Organic Aerosol Formation from Isoprene Photooxidation, Environ. Sci. Technol., 40, 1869-1877, 2006.

Kroll, J. H., Smith, J. D., Che, D. L., Kessler, S. H., Worsnop, D. R., and Wilson, K. R.: Measurement of fragmentation and functionalization pathways in the heterogeneous oxidation of oxidized organic aerosol, Phys. Chem. Chem. Phys., 11, 8005-8014, 2009.

Kulmala, M., Laaksonen, A., and Pirjola, L.: Parameterizations for sulfuric acid/water nucleation rates, J. Geophys. Res.-Atmos., 103, 8301-8307, doi:10.1029/97jd03718, 1998.

Lin, Y.-H., Budisulistiorini, S. H., Chu, K., Siejack, R. A., Zhang, H., Riva, M., Zhang, Z., Gold, A., Kautzman, K. E., and Surratt, J. D.: Light-absorbing oligomer formation in secondary organic aerosol from reactive uptake of isoprene epoxydiols, Environ. Sci. Technol., 48, 12012-12021, 2014.

Liu, Y., Monod, A., Tritscher, T., Praplan, A. P., DeCarlo, P. F., Temime-Roussel, B., Quivet, E., Marchand, N., Dommen, J., and Baltensperger, U.: Aqueous phase processing of secondary organic aerosol from isoprene photooxidation, Atmos. Chem. Phys., 12, 5879-5895, doi:10.5194/acp-12-5879-2012, 2012a.

Liu, Y., Siekmann, F., Renard, P., El Zein, A., Salque, G., El Haddad, I., Temime-Roussel, B., Voisin, D., Thissen, R., and Monod, A.: Oligomer and SOA formation through aqueous phase photooxidation of methacrolein and methyl vinyl ketone, Atmos. Environ., 49, 123-129, 2012 b. 
Ludwig, J. and Klemm, O.: Acidity of Size-Fractionated Aerosol-Particles, Water Air Soil Poll., 49, 35-50, doi:10.1007/bf00279508, 1990.

Menut, L., Bessagnet, B., Khvorostyanov, D., Beekmann, M., Blond, N., Colette, A., Coll, I., Curci, G., Foret, G., Hodzic, A., Mailler, S., Meleux, F., Monge, J.-L., Pison, I., Siour, G., Turquety, S., Valari, M., Vautard, R., and Vivanco, M. G.: CHIMERE 2013: a model for regional atmospheric composition modelling, Geosci. Model Dev., 6, 981-1028, doi:10.5194/gmd6-981-2013, 2013.

Mikhailov, E., Vlasenko, S., Rose, D., and Pöschl, U.: Mass-based hygroscopicity parameter interaction model and measurement of atmospheric aerosol water uptake, Atmos. Chem. Phys., 13, $717-$ 740, doi:10.5194/acp-13-717-2013, 2013.

Molnar, A. and Meszaros, E.: On the relation between the size and chemical composition of aerosol particles and their optical properties, Atmos. Environ., 35, 5053-5058, doi:10.1016/s13522310(01)00314-4, 2001

Morris, R. E., Bonyoung, K., Guenther, A., Yarwood, G., McNally, D., Tesche, T. W., Tonnesen, G., Boylan, J., and Brewer, P.: Model sensitivity evaluation for organic carbon using two multipollutant air quality models that simulate regional haze in the southeastern United States, Atmos. Environ., 40, 4960-4972, 2006.

Mouchel-Vallon, C., Bräuer, P., Camredon, M., Valorso, R., Madronich, S., Herrmann, H., and Aumont, B.: Explicit modeling of volatile organic compounds partitioning in the atmospheric aqueous phase, Atmos. Chem. Phys., 13, 1023-1037, doi:10.5194/acp-13-1023-2013, 2013.

Moya, M., Pandis, S. N., and Jacobson, M. Z.: Is the size distribution of urban aerosols determined by thermodynamic equilibrium?: An application to Southern California, Atmos. Environ., 36, 2349-2365, 2002.

Nenes, A., Pandis, S. N., and Pilinis, C.: ISORROPIA: A new thermodynamic equilibrium model for multiphase multicomponent inorganic aerosols, Aquat. Geochem., 4, 123-152, doi:10.1023/a:1009604003981, 1998.

Nguyen, T. B., Roach, P. J., Laskin, J., Laskin, A., and Nizkorodov, S. A.: Effect of humidity on the composition of isoprene photooxidation secondary organic aerosol, Atmos. Chem. Phys., 11, 6931-6944, doi:10.5194/acp-11-6931-2011, 2011a.

Nguyen, T. B., Laskin, J., Laskin, A., and Nizkorodov, S. A.: Nitrogen-containing organic compounds and oligomers in secondary organic aerosol formed by photooxidation of isoprene, Environ. Sci. Technol., 45, 6908-6918, 2011b.

Ovadnevaite, J., O'Dowd, C., Dall'Osto, M., and Ceburnis, D.: Detecting high contributions of primary organic matter to marine aerosol: A case study, Geophys. Res. Lett., 38, L02807, doi:10.1029/2010GL046083, 2011.

Pandis, S. N., Paulson, S. E., Seinfeld, J. H., and Flagan, R. C.: Aerosol formation in the photooxidation of isoprene and $\beta$ pinene, Atmos. Environ. A-Gen., 25, 997-1008, 1991.

Pankow, J. F.: An Absorption-Model of Gas-Particle Partitioning of Organic-Compounds in the Atmosphere, Atmos. Environ., 28, 185-188, doi:10.1016/1352-2310(94)90093-0, 1994.

Paredes-Miranda, G., Arnott, W. P., Jimenez, J. L., Aiken, A. C., Gaffney, J. S., and Marley, N. A.: Primary and secondary contributions to aerosol light scattering and absorption in Mexico City during the MILAGRO 2006 campaign, Atmos. Chem. Phys., 9, 3721-3730, doi:10.5194/acp-9-3721-2009, 2009.

Paulot, F., Crounse, J. D., Kjaergaard, H. G., Kroll, J. H., Seinfeld, J. H., and Wennberg, P. O.: Isoprene photooxidation: new insights into the production of acids and organic nitrates, Atmos. Chem. Phys., 9, 1479-1501, doi:10.5194/acp-9-1479-2009, 2009.

Petetin, H., Beekmann, M., Sciare, J., Bressi, M., Rosso, A., Sanchez, O., and Ghersi, V.: A novel model evaluation approach focusing on local and advected contributions to urban $\mathrm{PM}_{2.5}$ levels - application to Paris, France, Geosci. Model Dev., 7, 1483 1505, doi:10.5194/gmd-7-1483-2014, 2014.

Pun, B. K.: Development and initial application of the sesquiversion of MADRID, J. Geophys. Res.-Atmos., 113, D12212, doi:10.1029/2008jd009888, 2008.

Pun, B. K. and Seigneur, C.: Investigative modeling of new pathways for secondary organic aerosol formation, Atmos. Chem. Phys., 7, 2199-2216, doi:10.5194/acp-7-2199-2007, 2007.

Pun, B. K., Seigneur, C., and Lohman, K.: Modeling secondary organic aerosol formation via multiphase partitioning with molecular data, Environ. Sci. Technol., 40, 4722-4731, doi:10.1021/es0522736, 2006.

Raventos-Duran, T., Camredon, M., Valorso, R., Mouchel-Vallon, C., and Aumont, B.: Structure-activity relationships to estimate the effective Henry's law constants of organics of atmospheric interest, Atmos. Chem. Phys., 10, 7643-7654, doi:10.5194/acp10-7643-2010, 2010.

Renard, P., Siekmann, F., Gandolfo, A., Socorro, J., Salque, G., Ravier, S., Quivet, E., Clément, J.-L., Traikia, M., Delort, A.M., Voisin, D., Vuitton, V., Thissen, R., and Monod, A.: Radical mechanisms of methyl vinyl ketone oligomerization through aqueous phase $\mathrm{OH}$-oxidation: on the paradoxical role of dissolved molecular oxygen, Atmos. Chem. Phys., 13, 6473-6491, doi:10.5194/acp-13-6473-2013, 2013.

Renard, P., Siekmann, F., Salque, G., Demelas, C., Coulomb, B., Vassalo, L., Ravier, S., Temime-Roussel, B., Voisin, D., and Monod, A.: Aqueous-phase oligomerization of methyl vinyl ketone through photooxidation - Part 1: Aging processes of oligomers, Atmos. Chem. Phys., 15, 21-35, doi:10.5194/acp-1521-2015, 2015.

Robinson, A. L., Donahue, N. M., Shrivastava, M. K., Weitkamp, E. A., Sage, A. M., Grieshop, A. P., Lane, T. E., Pierce, J. R., and Pandis, S. N.: Rethinking Organic Aerosols: Semivolatile Emissions and Photochemical Aging, Science, 315, 1259-1261, 2007.

Sato, K., Nakao, S., Clark, C. H., Qi, L., and Cocker III, D. R.: Secondary organic aerosol formation from the photooxidation of isoprene, 1,3-butadiene, and 2,3-dimethyl-1,3-butadiene under high $\mathrm{NO}_{x}$ conditions, Atmos. Chem. Phys., 11, 7301-7317, doi:10.5194/acp-11-7301-2011, 2011.

Schmidt, H., Derognat, C., Vautard, R., and Beekmann, M.: A comparison of simulated and observed ozone mixing ratios for the summer of 1998 in Western Europe, Atmos. Environ., 35, 6277 6297, doi:10.1016/s1352-2310(01)00451-4, 2001.

Shrivastava, M., Fast, J., Easter, R., Gustafson Jr., W. I., Zaveri, R. A., Jimenez, J. L., Saide, P., and Hodzic, A.: Modeling organic aerosols in a megacity: comparison of simple and complex representations of the volatility basis set approach, Atmos. Chem. Phys., 11, 6639-6662, doi:10.5194/acp-11-6639-2011, 2011. 
Stier, P., Seinfeld, J. H., Kinne, S., and Boucher, O.: Aerosol absorption and radiative forcing, Atmos. Chem. Phys., 7, 5237-5261, doi:10.5194/acp-7-5237-2007, 2007.

Surratt, J. D., Murphy, S. M., Kroll, J. H., Ng, N. L., Hildebrandt, L., Sorooshian, A., Szmigielski, R., Vermeylen, R., Maenhaut, W., Claeys, M., Flagan, R. C., and Seinfeld, J. H.: Chemical composition of secondary organic aerosol formed from the photooxidation of isoprene, J. Phys. Chem., 110, 9665-9690, 2006.

Suzuki, T., Ohtaguchi, K., and Koide, K.: Application of Principal Components-Analysis to Calculate Henry Constant from Molecular-Structure, Comput. Chem., 16, 41-52, doi:10.1016/0097-8485(92)85007-1, 1992.

Tan, Y., Lim, Y. B., Altieri, K. E., Seitzinger, S. P., and Turpin, B. J.: Mechanisms leading to oligomers and SOA through aqueous photooxidation: insights from $\mathrm{OH}$ radical oxidation of acetic acid and methylglyoxal, Atmos. Chem. Phys., 12, 801-813, doi:10.5194/acp-12-801-2012, 2012.

Troen, I. and Mahrt, L.: A Simple-Model of the Atmospheric Boundary-Layer - Sensitivity to Surface Evaporation, Bound.Lay. Meteorol., 37, 129-148, doi:10.1007/bf00122760, 1986.

Trump, E. R. and Donahue, N. M: Oligomer formation within secondary organic aerosols: equilibrium and dynamic considerations, Atmos. Chem. Phys., 14, 3691-3701, doi:10.5194/acp-143691-2014, 2014.

Valorso, R., Aumont, B., Camredon, M., Raventos-Duran, T., Mouchel-Vallon, C., Ng, N. L., Seinfeld, J. H., Lee-Taylor, J., and Madronich, S.: Explicit modelling of SOA formation from apinene photooxidation: sensitivity to vapour pressure estimation, Atmos. Chem. Phys., 11, 6895-6910, doi:10.5194/acp-11-68952011, 2011.

Verwer, J. G.: Gauss-Seidel Iteration for Stiff ODEs from Chemical Kinetics, SIAM J. Sci. Comput., 5, 1243-1250, 1994.

Vestreng, V., Breivik, K., Adams, M., Wagner, A., Goodwin, J., Rozovskaya, O., and Pacyna, J. M.: Inventory Review 2005 Emission Data reported to CLRTAP and under the NEC Directive - Initial review for HMs and POPs, EMEP/MSC-W, available at: http://www.emep.int/publ/reports/2005/emep_technical_ 1_2005.pdf (last access: 8 April 2016), 2005.
Volkamer, R., Jimenez, J. L., San Martini, F., Dzepina, K., Zhang, Q., Salcedo, D., Molina, L. T., Worsnop, D. R., and Molina, M. J.: Secondary organic aerosol formation from anthropogenic air pollution: Rapid and higher than expected, Geophys. Res. Lett., 33, L17811, doi:10.1029/2006g1026899, 2006.

Wang, C., Goss, K.-U., Lei, Y. D., Abbatt, J. P. D., and Wania, F.: Calculating Equilibrium Phase Distribution during the Formation of Secondary Organic Aerosol Using COSMOtherm, Environ. Sci. Technol., 49, 8585-8594, doi:10.1021/acs.est.5b01584, 2015.

Wesely, M. L.: Parameterization of surface resistances to gaseous dry deposition in regional-scale numerical models, Atmos. Environ., 23, 1293-1304, 1989.

Xue, J., Lau, A. K. H., and Yu, J. Z.: A study of acidity on PM(2.5) in Hong Kong using online ionic chemical composition measurements, Atmos. Environ., 45, 7081-7088, 2011.

Zhang, Q., Jimenez, J. L., Canagaratna, M. R., Allan, J. D., Coe, H., Ulbrich, I., Alfarra, M. R., Takami, A., Middlebrook, A. M., Sun, Y. L., Dzepina, K., Dunlea, E., Docherty, K., DeCarlo, P. F., Salcedo, D., Onasch, T., Jayne, J. T., Miyoshi, T., Shimono, A., Hatakeyama, S., Takegawa, N., Kondo, Y., Schneider, J., Drewnick, F., Borrmann, S., Weimer, S., Demerjian, K., Williams, P., Bower, K., Bahreini, R., Cottrell, L., Griffin, R. J., Rautiainen, J., Sun, J. Y., Zhang, Y. M., and Worsnop, D. R.: Ubiquity and dominance of oxygenated species in organic aerosols in anthropogenically-influenced Northern Hemisphere midlatitudes, Geophys. Res. Lett., 34, L13801, doi:10.1029/2007g1029979, 2007.

Zhang, Y., Huang, J.-P., Henze, D. K., and Seinfeld, J. H.: Role of isoprene in secondary organic aerosol formation on a regional scale, J. Geophys. Res.-Atmos., 112, D20207, doi:10.1029/2007JD008675, 2007. 